\title{
Development of Optical Technologies for Monitoring Moisture and Particulate in Geothermal Steam
}

\author{
J.K. Partin \\ J.R. Davidson
}

August 2006

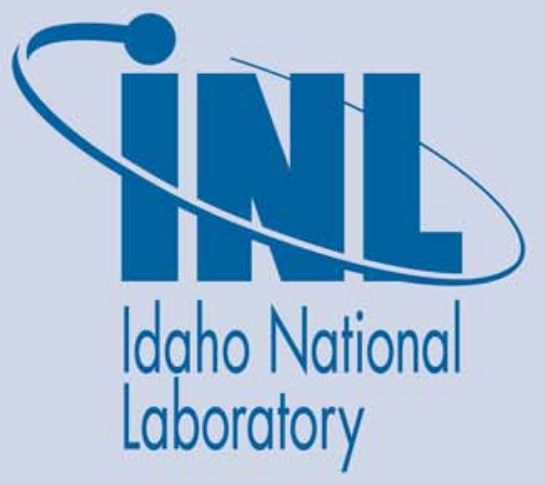

The INL is a U.S. Department of Energy National Laboratory operated by Battelle Energy Alliance 


\title{
Development of Optical Technologies for Monitoring Moisture and Particulate in Geothermal Steam
}

\author{
J.K. Partin \\ J.R. Davidson
}

August 2006

Idaho National Laboratory
Idaho Falls, Idaho 83415

Prepared for the

U.S. Department of Energy

Assistant Secretary for Energy Efficiency and Renewable Energy Under DOE Idaho Operations Office

Contract DE-AC07-05ID14517 


\begin{abstract}
The results of an investigation directed at evaluating the feasibility of using optical measurements for the real-time monitoring moisture and particulate in geothermal steam is described. The measurements exploit new technologies that have been developed for the telecommunications industry and include new solid state laser devices, large-bandwidth, high-sensitivity detectors and low loss optical fiber components. In particular, the design, fabrication, and in-plant testing of an optical steam monitor for the detection of moisture is presented. The measurement principle is based upon the selective absorption of infrared energy in response to the presence of moisture. Typically, two wavelengths are used in the measurements: a wavelength that is strongly absorbed by water and a reference wavelength that is minimally influenced by water and steam which serves as a reference to correct for particulate or droplet scattering. The two wavelengths are chosen to be as close as possible in order to more effectively correct for scattering effects.

The basic instrumentation platform developed for the in-situ monitoring of steam moisture can be modified and used to perform other measurements of interest to plant operators. An upgrade that will allow the instrument to be used for the sensitive detection of particulate in process streams has been investigated. The new monitor design involves the use of laser diodes that are much less sensitive to water and water vapor and more sensitive to scattering phenomena, as well as new processing techniques to recover these signals. The design reduces the averaging time and sampling volume, while increasing the laser probe power, enhancing particulate detection sensitivity. The design concept and initial laboratory experiments with this system are also reported.
\end{abstract}




\section{ACKNOWLEDGMENTS}

The authors would like to thank Plant Manager, Todd Sperry, and the operations staff at the Bonnett Geothermal for their help with the in-plant scoping experiments directed at measuring moisture in geothermal steam. The authors would also like to thank Dan Schochet of ORMAT, Inc. and the staff at the Brady Power Partners for their generous support of the deployment of the steam quality monitoring instrumentation in one of the turbine inlet lines at the Brady Plant. In particular, the authors want to thank the Plant Manager Eric Sponsler whose efforts were key to the successful deployment and evaluation of the device.

The authors would also like to thank their colleagues, Jim Lee, Randy Bewley, and Greg Mines, for their contributions to the work. Jim Lee worked on the electronic design and fabrication of the optical steam quality instrumentation. Randy Bewley is acknowledged for his efforts on the design, fabrication, and testing of the instrumentation upgrade for monitoring particulate. The authors are especially grateful to Greg Mines for helping them understand various aspects of geothermal process streams and their potential impact on the measurements and also for assisting with some of the field activities.

This work was supported by the U. S. Department of Energy, Assistant Secretary for Energy Efficiency and Renewable Energy, under DOE-NE Idaho Operations Contract DE-AC07-05ID14517. 


\section{CONTENTS}

ABSTRACT

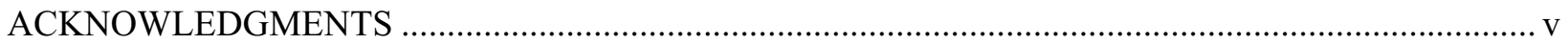

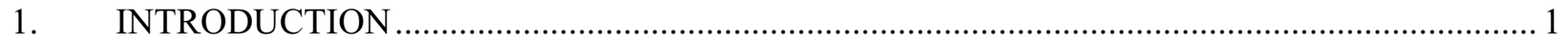

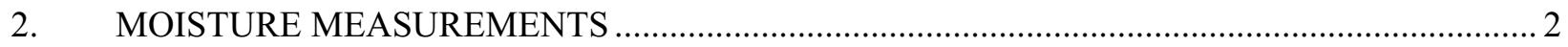

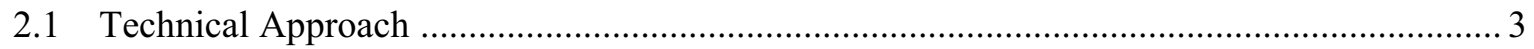

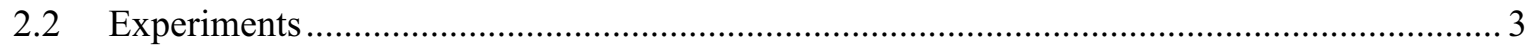

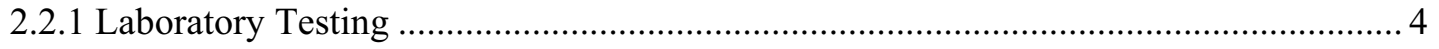

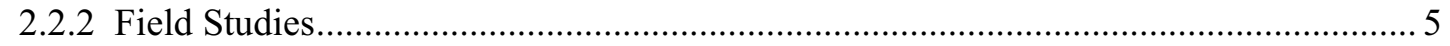

2.2.2.1 Slip-stream Sampling at the Bonnett Geothermal Plant .................................. 6

2.2.2.2 In-situ Monitoring in a Turbine Inlet Line at the Brady Power Plant.............. 9

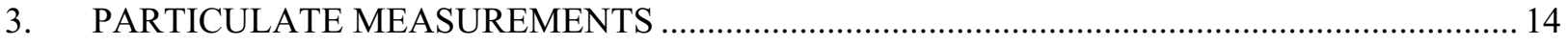

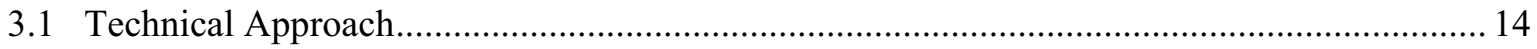

3.1.1 Laser-induced Breakdown Detection (LIBD) ........................................................ 14

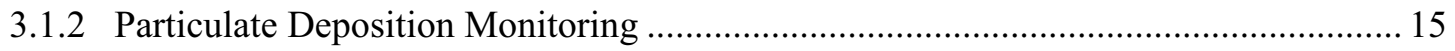

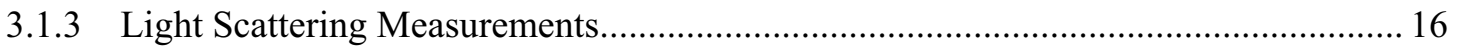

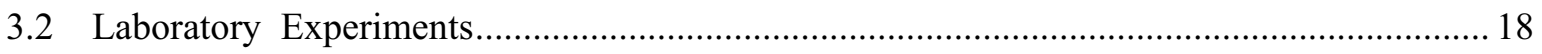

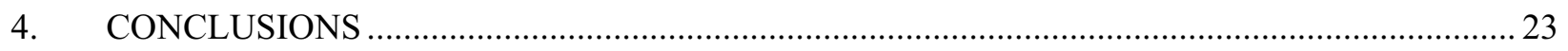

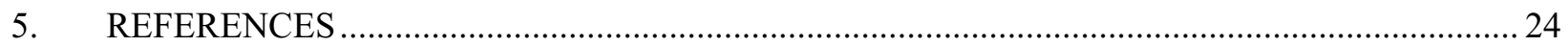

FIGURES

1. Water vapor and liquid water absorption in the near-infrared spectral region ............................... 2

2. Laboratory setup for evaluating candidate diodes for use in steam moisture measurements ............. 4

3. Change in diode signal as a function of steam moisture content................................................... 5

4. Well head installation of steam moisture monitoring instrumentation at the Bonnett Geothermal Plant (a) Well head installation overview (b) Well head installation close-up ............................... 6

5. Installation of steam moisture monitoring instrumentation in the ejector line at the Bonnett Geothermal Plant 
6. Installation of steam moisture monitoring instrumentation in the flash separator vessel exit pipe at the Bonnett Geothermal Plant

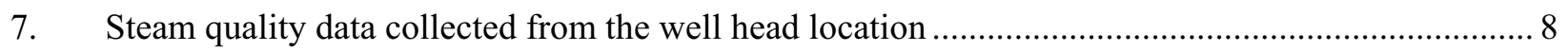

8. Steam quality data collected from the steam separator exit pipe............................................. 8

9. Steam quality data collected from the steam ejector inlet pipe ….............................................. 9

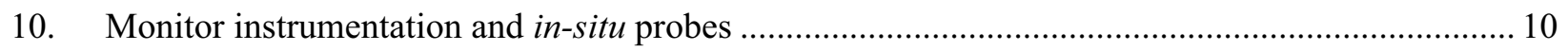

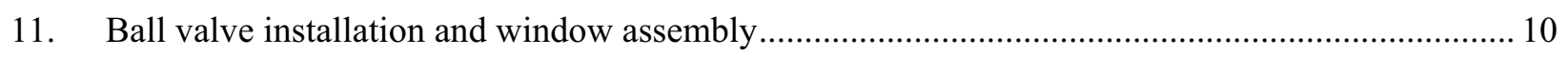

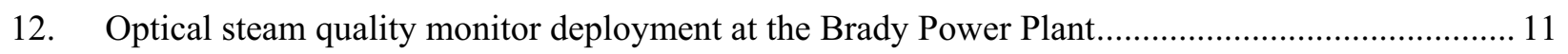

13. Steam quality monitor data collected during water washing procedure ..................................... 12

14. Steam monitor probe window condition after 150 day deployment in turbine inlet line ................ 13

15. Laser-induced breakdown detection (LIBD) concept for detecting and analyzing particulate ........ 14

16. Change in steam quality monitor signal output due to particulate deposition, or fouling, on the

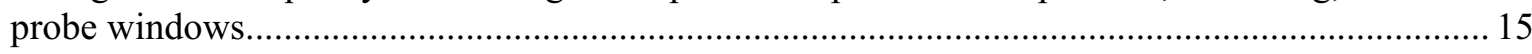

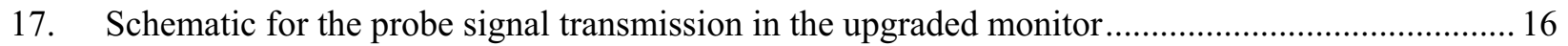

18. Schematic of the signal acquisition and processing in the upgraded monitor ............................... 17

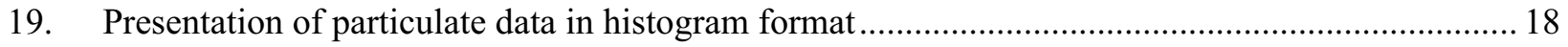

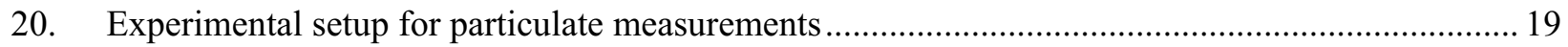

21. Comparison of the response of the new particulate monitoring diode, moisture sensing diode, and previously used reference diode to "dry" and "wet" conditions................................................... 19

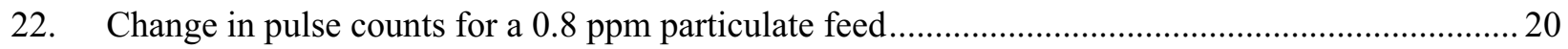

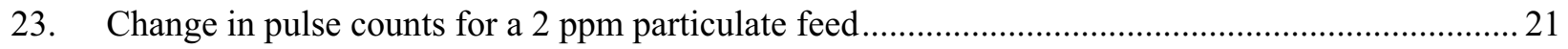

24. Change in pulse counts for a 5 ppm particulate feed............................................................. 21

25. Change in pulse counts for a $7 \mathrm{ppm}$ particulate feed............................................................ 22 


\section{Development of Optical Technologies for Monitoring Moisture and Particulate in Geothermal Steam}

\section{INTRODUCTION}

Geothermal plants contain gaseous, liquid, and particulate species in process streams that may require abatement to minimize equipment damage, maximize performance and/or meet regulatory requirements. These abatement processes involve the use of costly chemicals and/or the consumption of energy; and in addition, are conservatively applied, in part, because the targeted species are only measured periodically. Consequently, engineers at the Idaho National Laboratory (INL) have been investigating the application of devices that have been developed for the telecommunications industry in the design of robust instrumentation for monitoring various process parameters (Partin and Jeffery, 1998; Partin and Davidson, 2002; Partin, Davidson, Sponsler, and Mines, 2004). The goal is to develop new, user-friendly technologies for the real-time control of abatement processes in geothermal plants to make them more efficient and less costly to operate.

The measurement of steam moisture, commonly referred to as steam quality, is important because of the impact that excessive moisture can have on turbine performance and maintenance costs. Moisture can be introduced into the steam line by either inadequate phase separation processes or during steam "washing" employed to reduce particulate, chlorides, and other chemicals to levels that are not as damaging to equipment. If too much water is added, the washing process may actually make the problem worse. Droplets entrained in the steam can erode turbine internals, while particulate and other contaminates dissolved or entrained in the moisture can deposit on and scale turbine components. The principal impurities of concern are silica, iron, aluminum, and chlorides since these elements are associated with scaling and corrosion (Jung, 1995; Gallup, 1998). Both scaling and erosion adversely impact turbine efficiency, which also decreases as the amount of moisture in the steam increases. Decreases in turbine efficiency reduce the power output and lower revenue streams. For a $50 \mathrm{MW}$ plant the revenue losses due to a $1 \%$ loss in efficiency can be as high as $\$ 175,000$ per year, depending upon the cost of electricity. Eventually, the turbines must be removed from service for cleaning, resulting in additional lost revenues and maintenance costs. In some cases, very expensive turbine components have to be replaced.

Calorimeters are most commonly used for the measurement of steam moisture, but difficulties with sensitivity, accuracy, and range limit their suitability for use in many applications. A number of factors can impact the sensitivity and accuracy of calorimeter data (Jung, 1995). The measurement of moisture with this instrument is based upon the assumption of a constant enthalpy expansion from the process pressure. Any heat loss from the measurement volume results in a deviation from this assumption and introduces error. The gases found in geothermal streams may also have different Joule-Thompson (dT/dP) coefficients; and consequently, a mixture of these gases and steam may not accurately correlate with the pressure and temperature curves used to interpret the data. In addition, because the calorimeter uses a side-stream flow it is difficult to obtain a representative sampling of the stream, even when multi-port probes are used. The calorimeter range is also restricted by its ability to produce a measurable superheat for determining steam quality. (For a 50 psia process stream expanded to one atmosphere, this minimum limit on the inlet steam quality is on the order of $97 \%$.) The measurement of impurity levels in steam is typically performed by conductivity or trace chemistry means. Conductivity measurements are impacted by dissolved gases and therefore are not useful for detecting trace amounts of solids. Trace chemical techniques can be very accurate but are labor-intensive and require long time lags between sampling and analyses. 
In order to address some of these measurement limitations, a new instrument has been developed for the real-time, in-situ monitoring of steam quality and purity (in this case, particulate loading). The quality measurement is based upon the selective absorption of infrared radiation for determining the water content of moist air. The method takes advantage of the strong rotational and vibrational absorption bands produced by water vapor (steam) and liquid water in near-infrared ranges (Figure 1) of the electromagnetic spectrum (Palmer and Williams, 1974; Kou, et. al., 1993). Two wavelengths are typically used in the measurements: 1) a wavelength that is strongly absorbed by water and 2) a reference wavelength that is minimally influenced by water and steam; and thereby, serves as the reference to correct for particulate or droplet scattering. The two wavelengths are chosen to be as close as possible in order to more effectively correct for scattering effects. The purity measurement uses the optical attenuation and scattering produced by wavelengths that are much less sensitive to water and water vapor. These wavelengths are also more sensitive to scattering phenomena indicative of the presence of particulate. In addition, special processing techniques are employed to recover these signals.

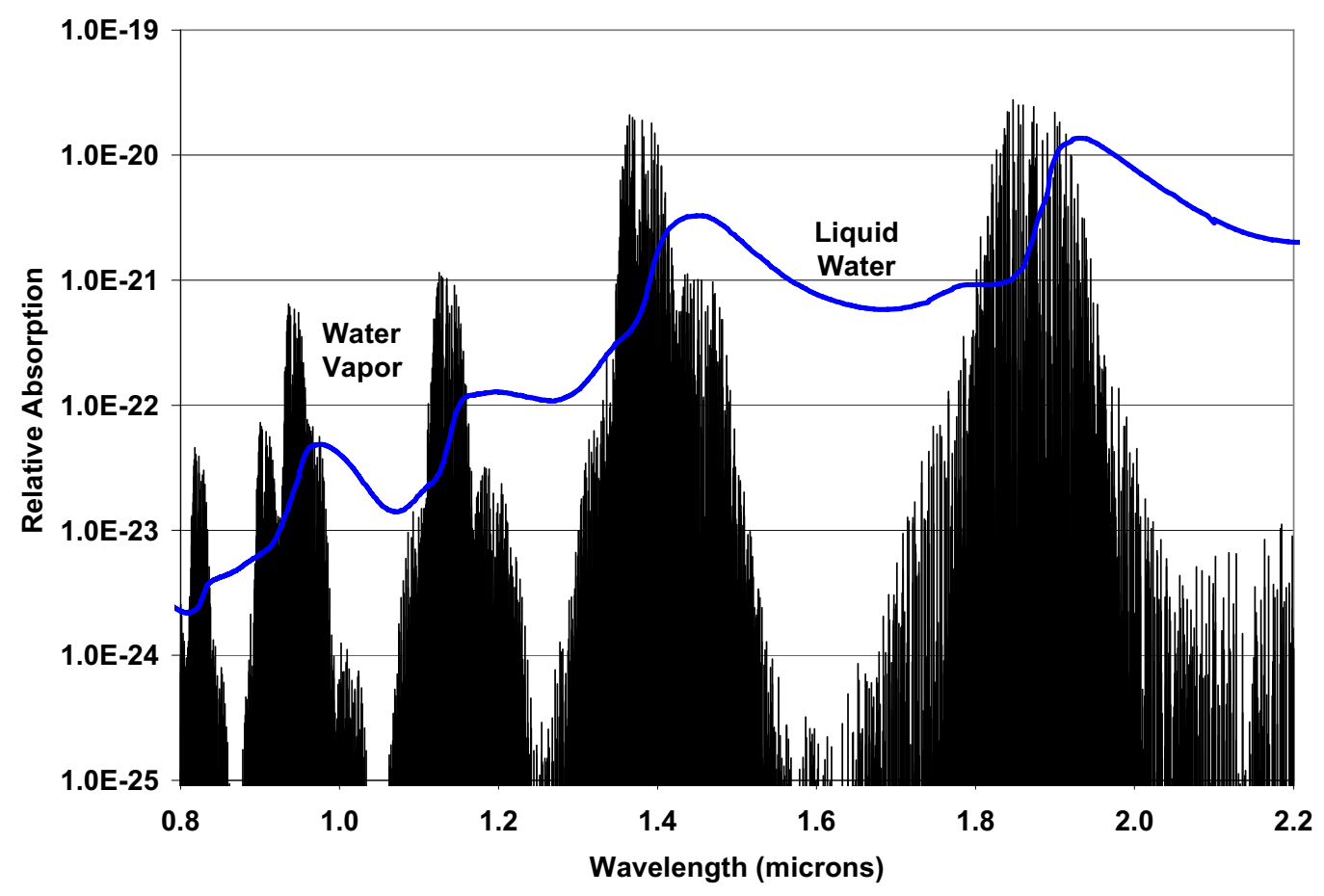

Figure 1. Water vapor and liquid water absorption in the near-infrared spectral region.

While these techniques have been known for decades, they have not been widely used due to the cost and complexity of the instrumentation required. In general, large-scale, Nerst glowers were needed to provide sufficient infrared radiation for the measurements. In order to sense changes with these low intensity, incoherent sources, the measurements were typically conducted in the long-wave region of the electromagnetic spectrum where water is very strongly absorbing. Measurements in this region are not compatible with remote sensing over optical fibers or the use of room temperature detectors (Wexler, 1963). The INL is investigating the re-engineering of these types of systems to incorporate semiconductor emitter and detector technologies that are compact, relatively inexpensive, and compatible with standard low-loss optical fiber technology. All of these components operate at room temperature and can be packaged as devices that could be directly interfaced to steam lines and used to collect and transmit data from locations throughout the plant. 


\section{MOISTURE MEASUREMENTS}

\subsection{Technical Approach}

The steam moisture measurement uses changes in signal intensities that are governed by Beer's Law. This law states that if a beam of parallel light rays of wavelength, $\lambda$, passes through an absorbing media, the original intensity, $\mathrm{I}_{0}$, of this radiation will decrease by an amount that is dependent upon the number of molecules present, or the concentration of the absorbing medium, as follows,

$\mathrm{I}=\mathrm{I}_{0} \exp [-\varepsilon(\lambda) \rho \mathrm{L})$

In this expression, $\mathrm{I}$ is the intensity of the light measured at a distance $\mathrm{L}$. $\mathrm{I}_{0}$ is the initial light intensity. $\varepsilon$ is an absorption constant for the medium that is dependent upon material composition and the wavelength of the light. $\rho$ is the density of the medium and $\mathrm{L}$ is the absorption path.

In addition to signal loss, or attenuation, that is caused by absorption, the light may also be attenuated by scattering and through reflection from surfaces.

$I_{1}=\beta I_{01} \exp \left[-\varepsilon(\lambda)_{1} \rho L\right)$

In this expression, $I_{01}$ is the initial intensity of a probe beam of wavelength, $\lambda_{1}$, and $\beta$ is a factor, approximately independent of wavelength that accounts for scattering and reflective losses, as well as for geometric losses as the beam propagates through the measurement volume. If a wavelength, $\lambda_{2}$, of light is not absorbed by the medium, the intensity is:

$\mathrm{I}_{2}=\beta \mathrm{I}_{02}$

With a two-wavelength technique, a wavelength, $\lambda_{1}$, is selected that is absorbed by liquid water, but not by steam (vapor), and another wavelength, $\lambda_{2}$, that is not absorbed by either steam or water, and therefore, serves as a reference. Equations (2) and (3) can then be combined to give

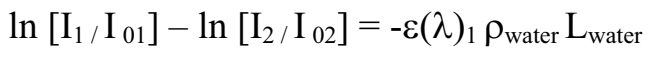

$I_{1}$ is the intensity of the water-absorbing wavelength, $\lambda_{1}$, and $I_{2}$ is the intensity of the reference wavelength, $\lambda_{2}$, after passing through the test section. $\mathrm{I}_{01}$ and $\mathrm{I}_{02}$ are the intensities of $\lambda_{1}$ and $\lambda_{2}$, respectively, with no water present. It should be noted that non-absorptive losses have been cancelled in this process and are no longer a factor. $\mathrm{L}_{\text {water }}$ is the absorption at a pathlength, or material thickness, of $\mathrm{L}$ through water. The constant, $\varepsilon(\lambda)_{1}$, generally must be established through calibration. The wavelength, $\lambda_{1}$, could be also chosen to be a wavelength that is more strongly absorbed by steam than liquid water, allowing for an independent determination of vapor concentration. This selection may give more sensitive results for some process conditions.

\subsection{Experiments}

The initial goal of the experimental work was to establish if commercially-available diode devices could be sensitive enough to produce reliable signal changes in response to small $(\leq 0.1 \%)$ changes in steam quality. The second goal was to determine if this sensitivity could be preserved when the measurements were conducted in an actual geothermal process stream. The third goal was to develop optical 
interfaces for performing the measurement in a steam line, select a site for the installation and evaluation of the instrument, and then determine if the sensitivity can be maintained in this extended in-situ deployment application.

\subsubsection{Laboratory Testing}

Nine diodes emitting in wavelength regions containing water vapor bands published in the literature were procured for testing. Both broadband, low-intensity light emitting diodes (LEDs) and narrower band, high-intensity laser diodes were evaluated to determine their relative sensitivities to the presence of water in steam. A small laboratory steam loop was also configured and instrumented for the experiments. As illustrated in Figure 2, steam was produced using a commercial generator and propagated to a heated and insulated one-meter sample chamber using a heated, six-meter long transfer hose. By controlling the heat added to the steam using the six-meter transfer hose, it was possible to control the amount of superheat available to the system. The windowed test chamber was placed in line with a throttling calorimeter in order to provide an independent measurement of moisture. The diode response was measured over the range of the calorimeter, approximately $96-100 \%$ at a line pressure of around 80 psig.

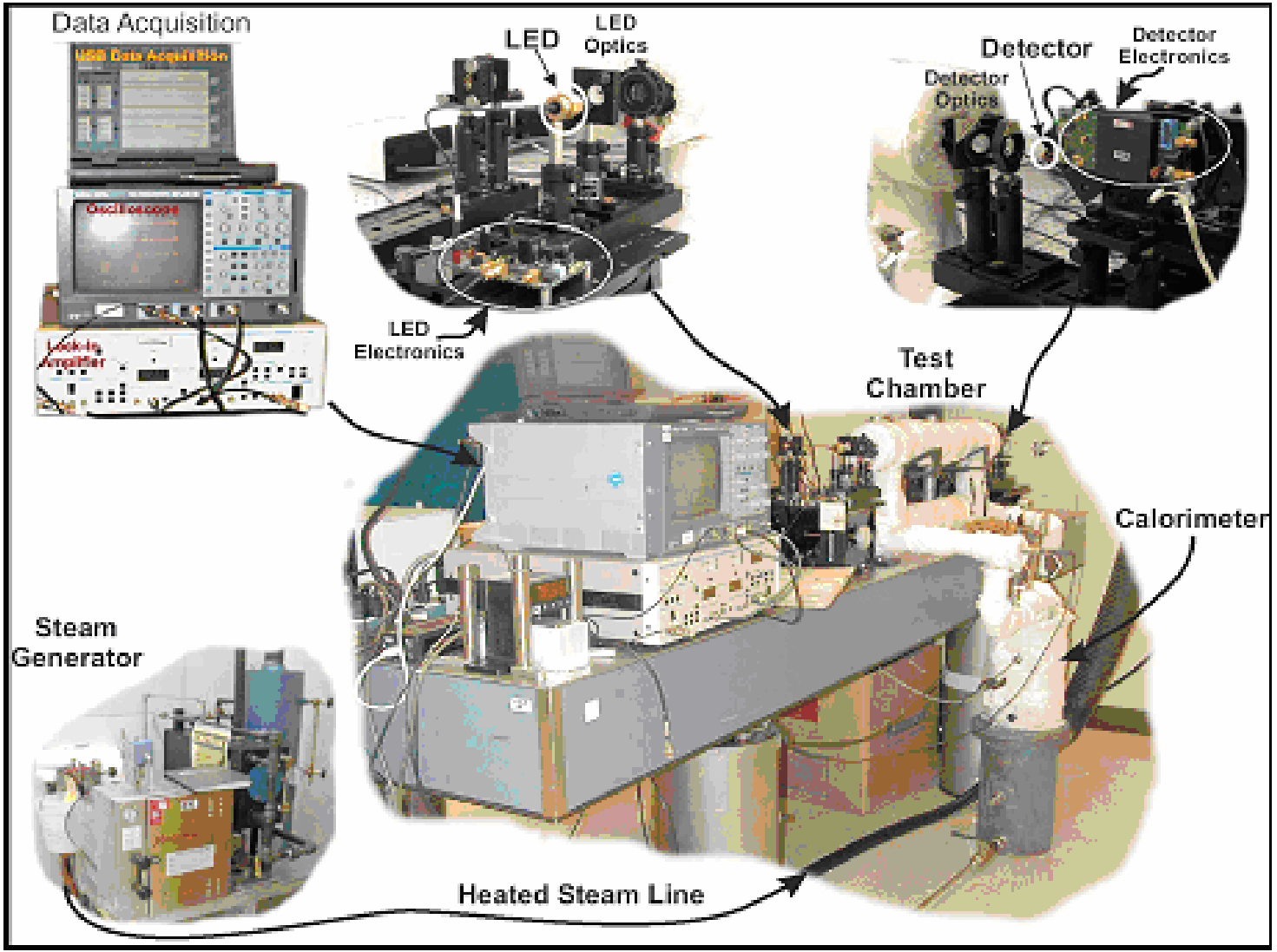

Figure 2. Laboratory setup for evaluating candidate diodes for use in steam moisture measurements.

A typical data run is presented in Figure 3. The plot records the optical signal change for one of the LED devices averaged over a 10 second interval, along with the system (line) pressure, and the calorimeter temperature. The $\pm 2.5 \mathrm{psig}$ variation seen in the pressure is caused by the normal cycling of the steam generator. Referring to Figure 3, at approximately 10:30 the calorimeter temperature reads $212^{\circ} \mathrm{F}$, the steam generator pressure reads nominally 80 psig, indicating a steam quality of approximately $96 \%$. 
As the line is heated the calorimeter temperature increases, indicating a higher steam quality.

Considerable modulation of the diode signal is seen to occur with small changes in steam moisture as shown by the recorded calorimeter temperature, indicating that a sensitive measurement of quality is possible. (Signal-to-noise analyses indicate that changes in quality on the order of $0.05 \%$ could be detected over the $96-100 \%$ quality range.) The steam appears to be dry when the calorimeter records a temperature of $284^{\circ} \mathrm{F}$ at approximately 11:05. At 11:17 the heated hose is deactivated, reducing the amount of heat added to the steam, and consequently decreasing the steam quality. The diode is seen to respond very rapidly to this change while the calorimeter is very slow to react. The steam generator is turned off at 11:30 and the optical signal is seen to return to approximately $100 \%$ of its original value.

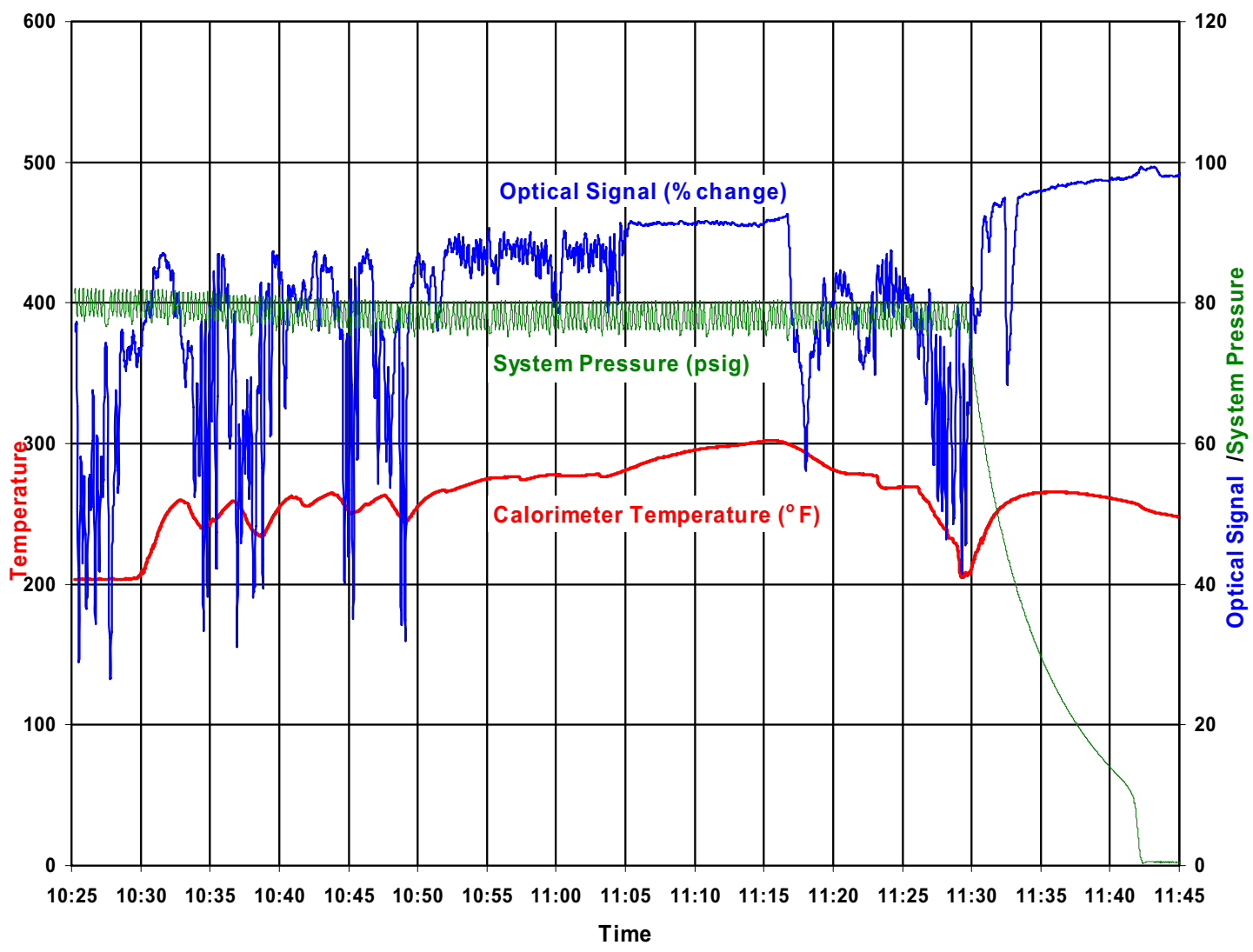

Figure 3. Change in diode signal as a function of steam moisture content.

The laboratory studies concluded that the laser diode devices were superior in performance to the broadband light emitting diode devices, and had added advantage in that they were also cheaper and easier to obtain.

\subsubsection{Field Studies}

Based upon the data from the laboratory studies, three laser diodes were selected for packaging into a system that could be deployed and further evaluated in a geothermal process stream. In addition to determining if the laboratory measurement sensitivity could be maintained, an additional goal of this field testing was to determine if there were any interference from absorption bands due to chemical species, such as carbon dioxide, that are present in the geothermal steam. 


\subsubsection{Slip-stream Sampling at the Bonnett Geothermal Plant}

The field evaluation was conducted at the Bonnett Geothermal Plant at Cove Fort, Utah, June 24July 5, 2002. During the evaluation, steam from three locations including a well head, a separator vessel exit steam pipe, and an ejector line was sampled and measured. The experimental setup for the measurement of the well head steam is shown in Figure 4. The installations at the steam separator vessel exit pipe and the steam ejector line are presented in Figures 5 and 6 respectively.

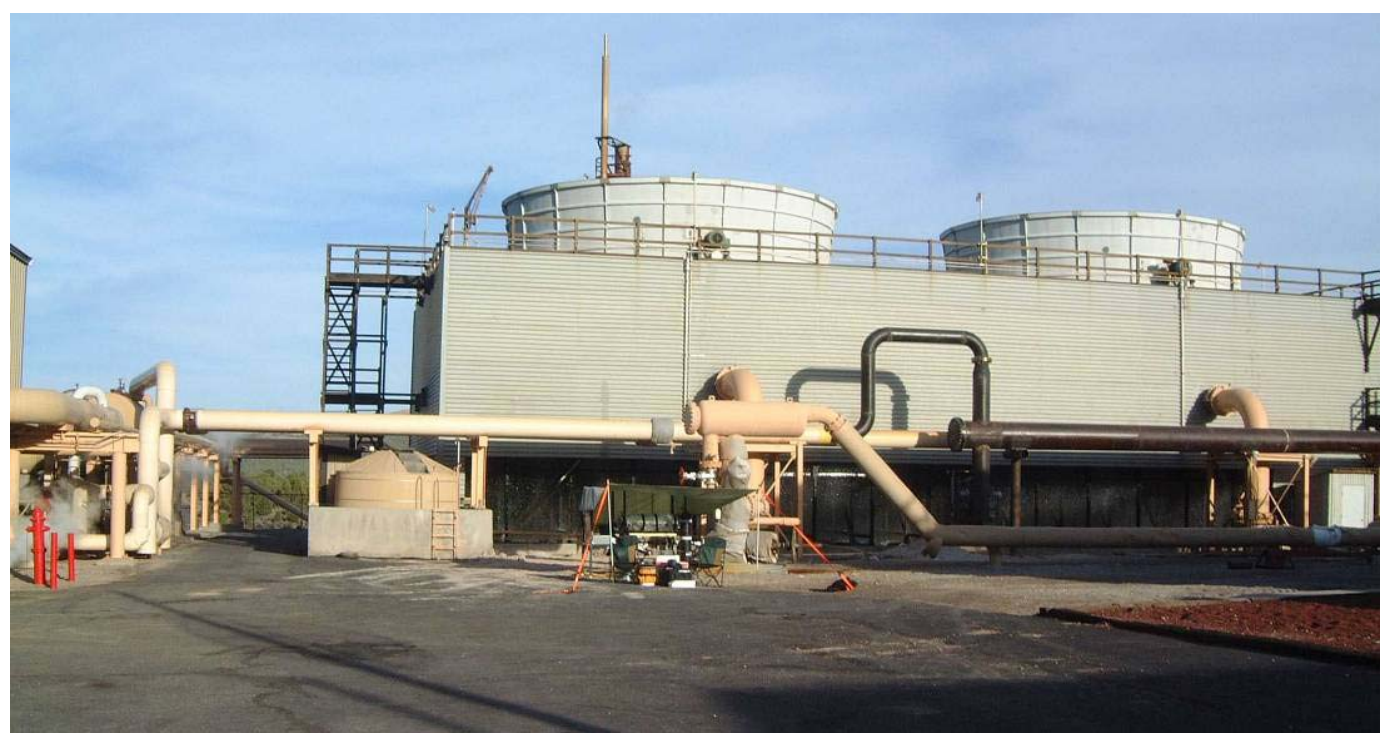

(a) Well head installation overview

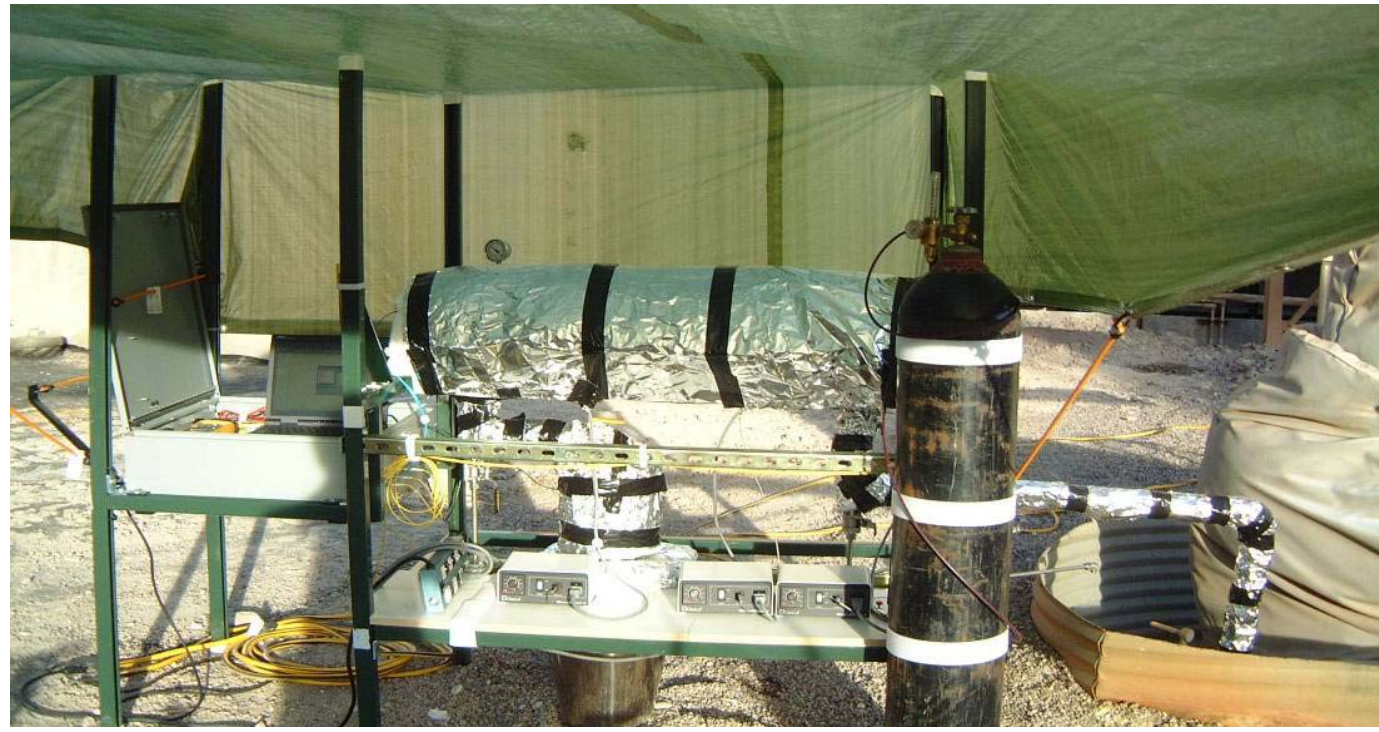

(b) Well head installation close-up

Figure 4. Well head installation of the steam moisture monitoring instrumentation at the Bonnett Geothermal Plant. 


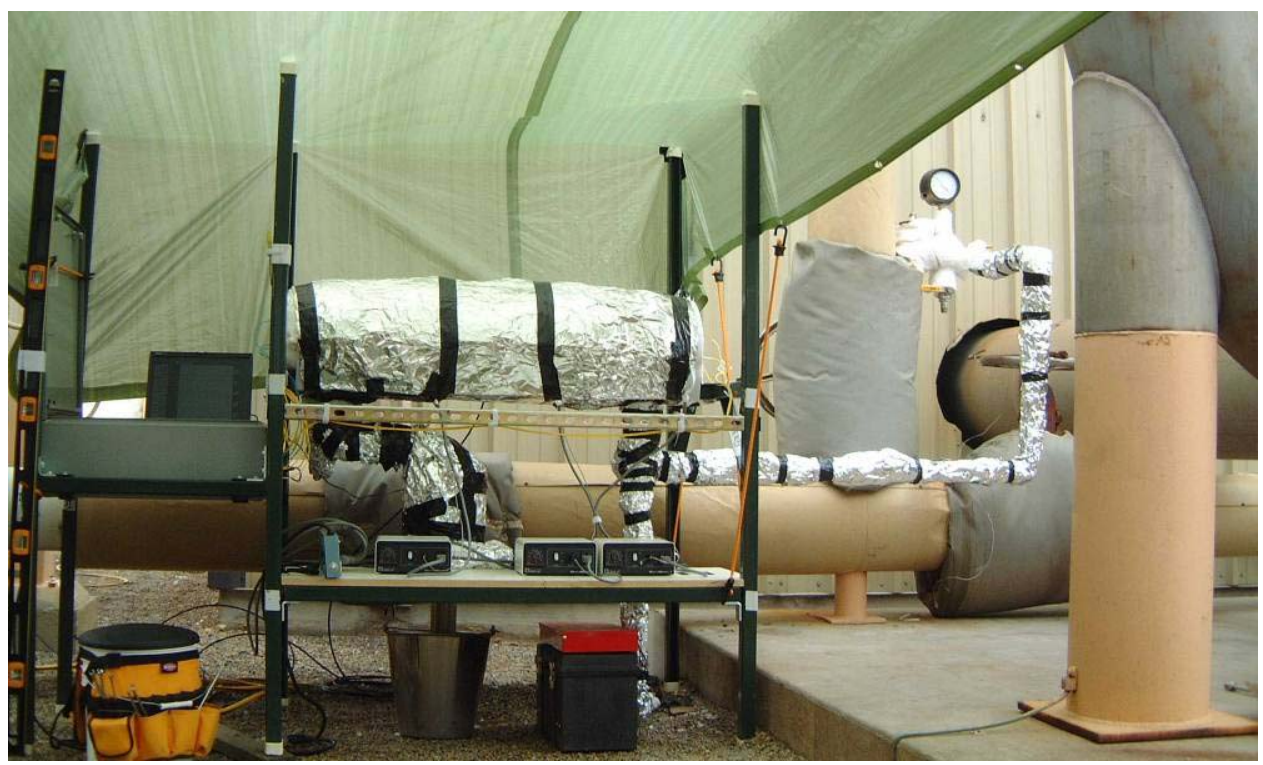

Figure 5. Installation of the steam moisture monitoring instrumentation in the steam ejector line at the Bonnett Geothermal Plant.

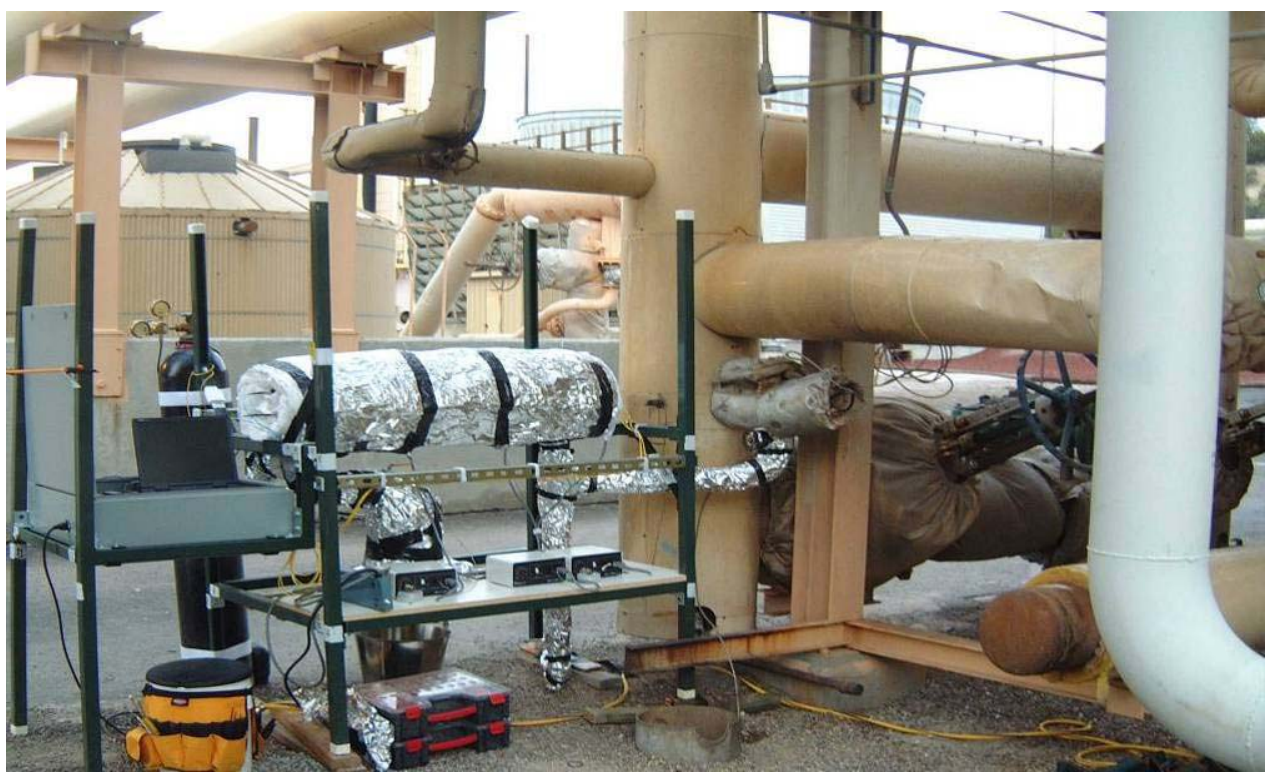

Figure 6. Installation of the steam moisture monitoring instrumentation in the steam separator vessel exit pipe at the Bonnett Geothermal Plant.

In the experiments, the process steam was sampled into a well insulated, flow-through cell approximately 1 meter in length and 0.25 meters in diameter, configured with three optical ports. The optical emitters, receivers and associated electronics were housed in the box located to the left of the cell (Figures 4-6). Changes in the optical signals were digitized and transferred to a personal computer where they were displayed and logged. Since the process streams contained some unknown fraction of moisture the cell was configured with heaters so that the process steam could be dried. This capability allowed the researchers to introduce controlled changes in the process stream and observe the instrument response to 
these changes. The optical signals were compared with steam quality data collected with a throttling calorimeter installed in the sampling line near the exit port of the optical cell. Data collected at the three sampling locations is presented in Figures 7-9.

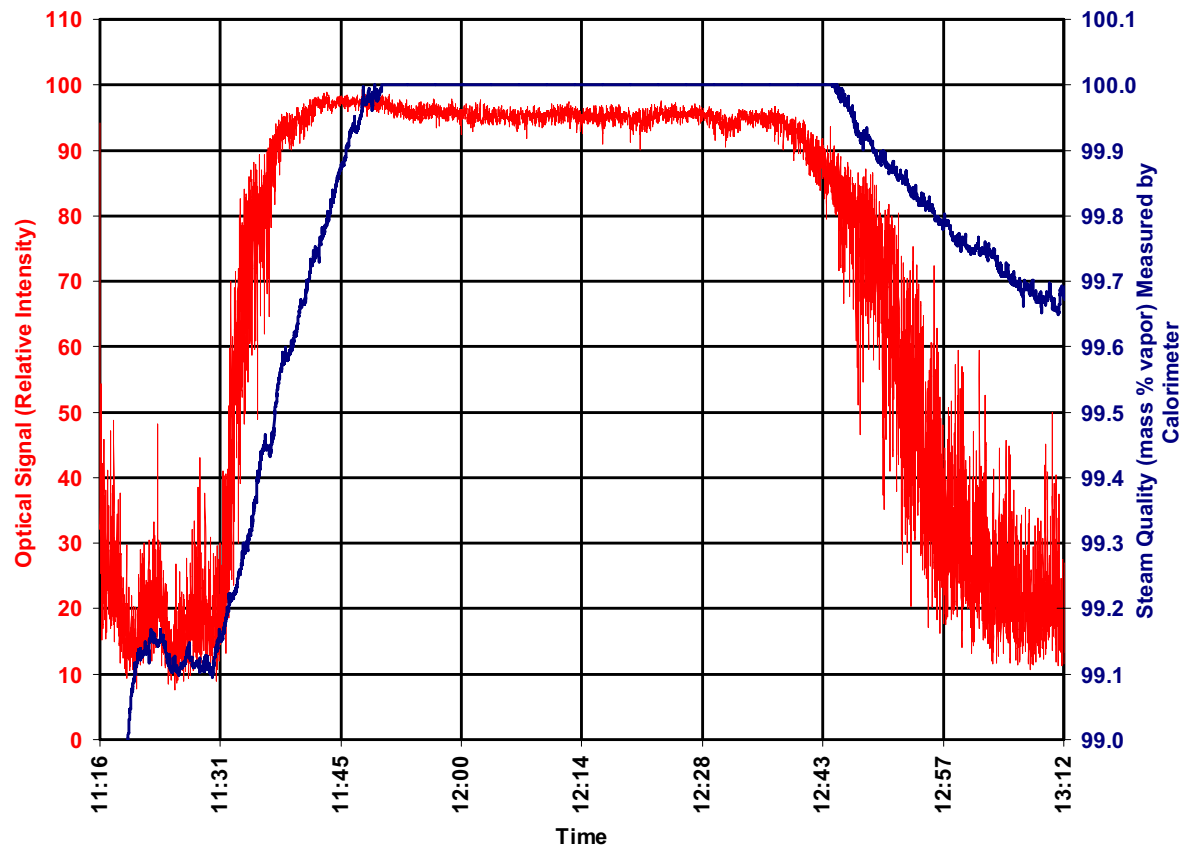

Figure 7. Steam quality data collected from the well head location.

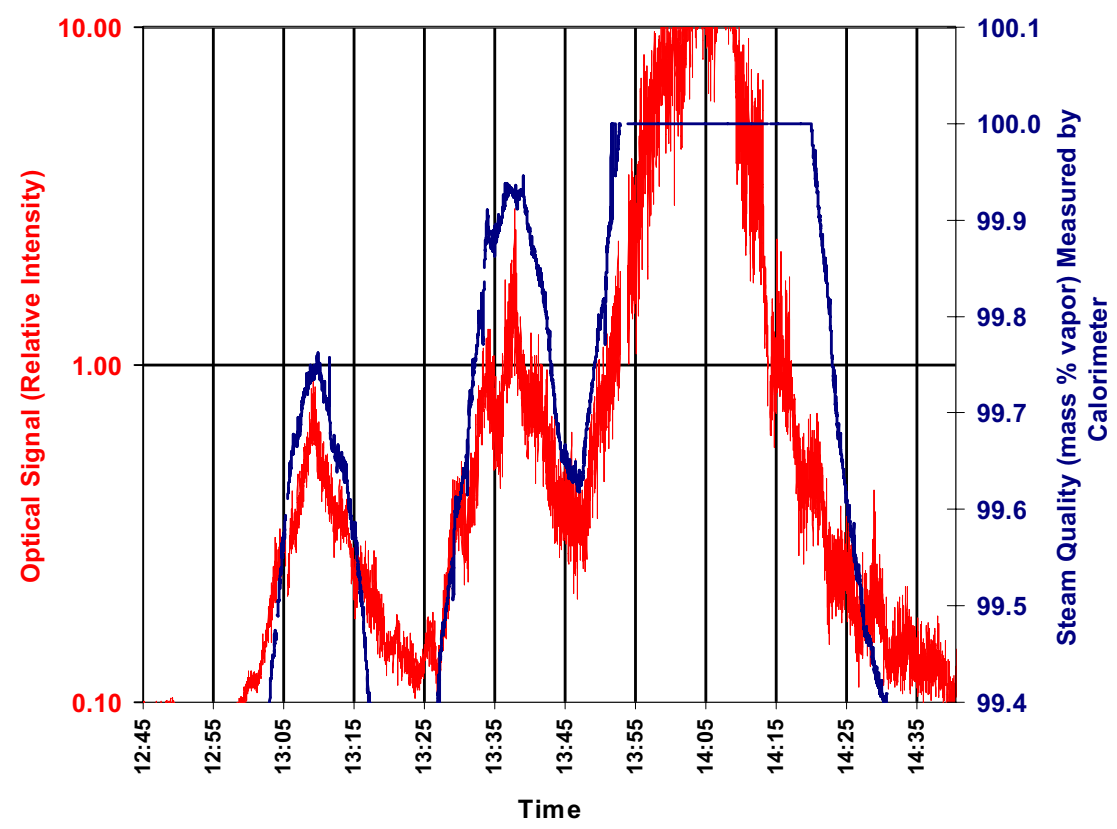

Figure 8 . Steam quality data collected from the steam separator exit pipe. 


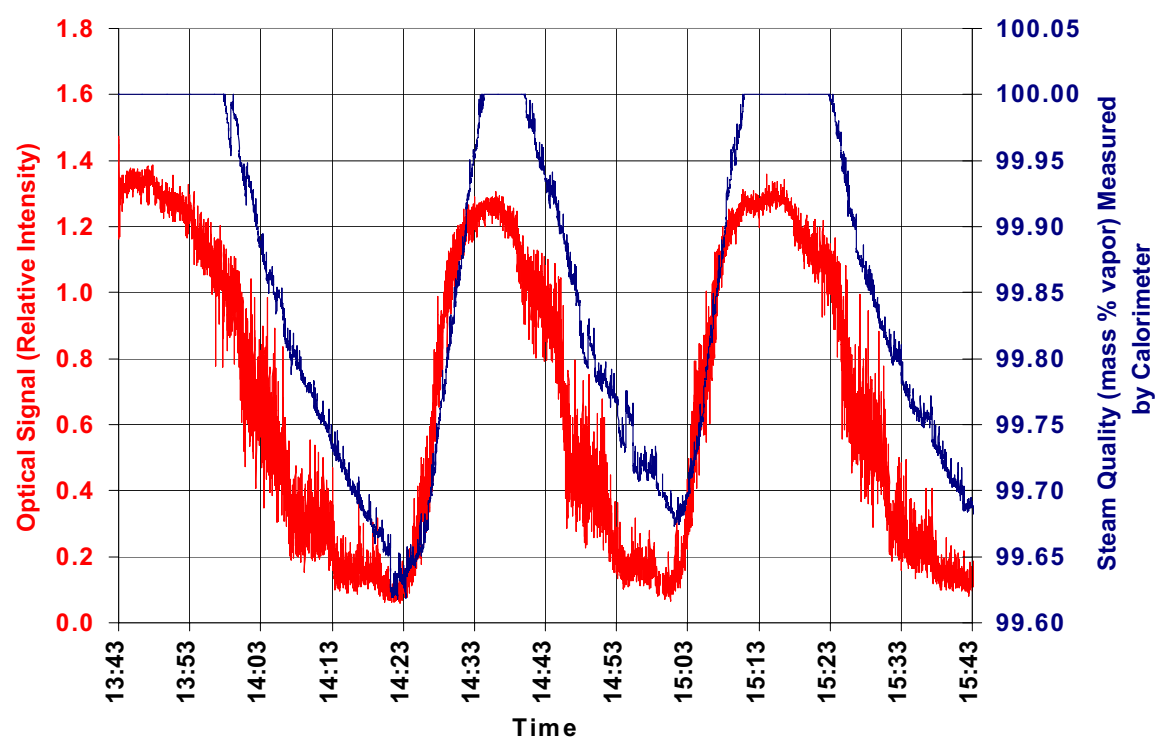

Figure 9. Steam quality data collected from the steam ejector inlet line.

Data from the field experiments conducted at the Bonnett Plant indicated that the optical technique was quite sensitive to changes in steam quality for some of the diodes tested. In particular, the response of the diode with the most sensitivity to water vapor produced the largest attenuation over the conditions tested at the plant. Referring to data collected from the ejector inlet experiments, shown in Figure 9, a 93\% attenuation of the optical signal was observed over the 1-meter cell path length for a $0.3 \%$ change in quality as measured by the calorimeter sampled. This implies that even with a fairly crude optical measurement sensitivity of $10 \%$, changes in quality on the order of $0.03 \%$ are achievable. In addition, the optical measurement produced a faster response to changes in moisture when compared to the calorimeter and can operate over a wider range of moisture conditions. No interferences from other gas constituents were observed with the diodes tested. The optical signal noise is also seen to decrease as the test cell steam quality approaches $100 \%$. This phenomenon might also be used to determine when a system conditions change from "dry" to "wet" for some process monitoring scenarios.

\subsubsection{In-situ Monitoring in a Turbine Inlet Line at the Brady Power Plant}

Building upon the results of this testing, the instrumentation was then modified for evaluation over an extended period of operation in a plant steam line to determine if this sensitivity could be maintained in an in-situ deployment application. Improved window ports were developed and tested for use in this application, and Brady Power Partners, an ORMAT Group Company, agreed to assist in the installlation and operation of the device in a turbine inlet line at the Brady Geothermal plant located near Fallon, NV. This plant was well-suited for the in-situ evaluation, since water washing was periodically used in the operation to reduce turbine scaling, providing known changes in the steam moisture content for the monitor to track. The goal of the long-term deployment was to assess the measurement sensitivity, reliability, stability, and to identify any potential maintenance issues with the instrument that would be associated with extended periods of unattended operation in a plant environment. The monitor was installed in a turbine inlet line at the Brady Geothermal Power Plant on August 20, 2003 and operated for 150 days. 
The optical steam quality instrumentation is shown in Figure 10. The monitor consists of an electronics package, which in addition to a data logger, includes laser diodes, beam combiners/separators, and detectors that are fiberoptically-coupled to a pair of specially designed optical probes. The probes are aligned across the process stream of interest. This allows data to be collected in a volumetric cross section extending across the entire process stream, resulting in the collection of more representative data for higher accuracy measurements that are applicable to all flow regimes. The optical signals are collimated into a beam of radiation that is transmitted through a sapphire window and across the process stream where it is collected by an identical probe assembly and transmitted back to the electronics box for analyses. (Sapphire windows have a combination of physical, chemical, and optical properties that allow them to operate in high pressure, high temperature, and chemically caustic environments.) The fiber optic coupling to the probes allows them to be located at distances up to 1 kilometer from the electronics package.

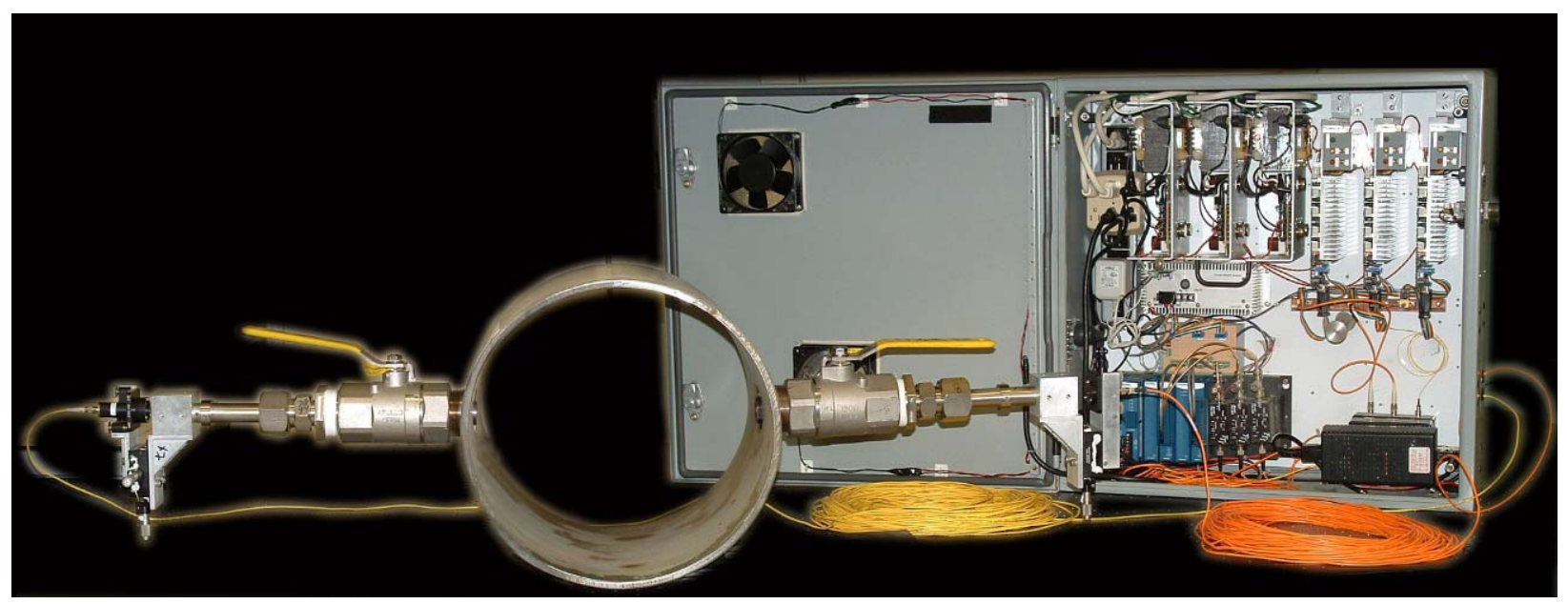

Figure 10. Monitor instrumentation and in-situ probes.

The stainless steel probes are designed for "hot tap" insertion into the process stream using a ball valve installation, as illustrated in Figure 11. The process flow across the windows minimizes the formation of condensate and particulate deposition in lieu of using active heating or gas purging to keep the windows clear. The probes can also be easily removed for window cleaning or replacement without shutdown of the process stream.

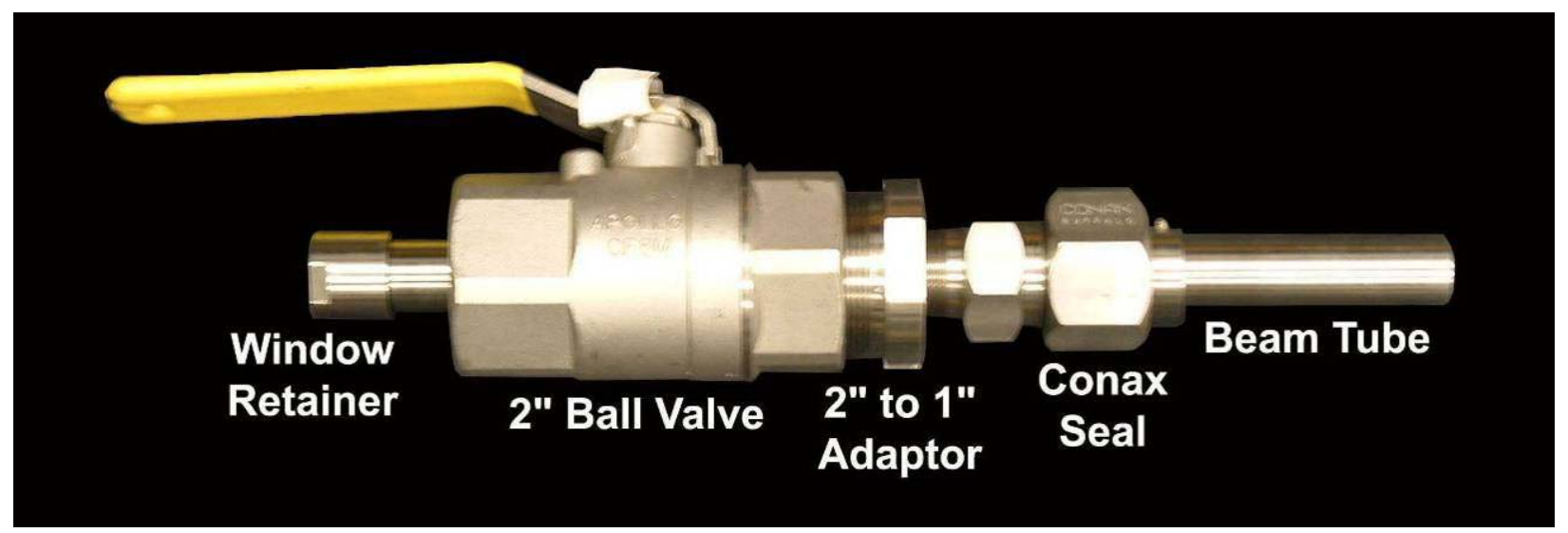

Figure 11. Ball valve and window assembly. 
The 0-2.5 volt analog signals, collected from the monitor, were acquired using a National Instruments Fieldpoint data logging system, which also enabled the data to be downloaded for display and processing on a user computer through a built-in ethernet connection. FTP and WEB-based access was also available. The data were archived on a 512 megabyte flash card with a new file generated every 24 hours. If a power failure occurred the system would reboot and automatically generate a new data file. The optical probes were inserted into a turbine inlet line using aligned ball valve installations located immediately upstream of the turbine and downstream from a series of throttling valves, as shown in Figure 12. The optical signals, used for the determination of steam quality, were fiberoptically-coupled from the probes to the instrumentation box located in the plant control room, as shown in Figure 12.

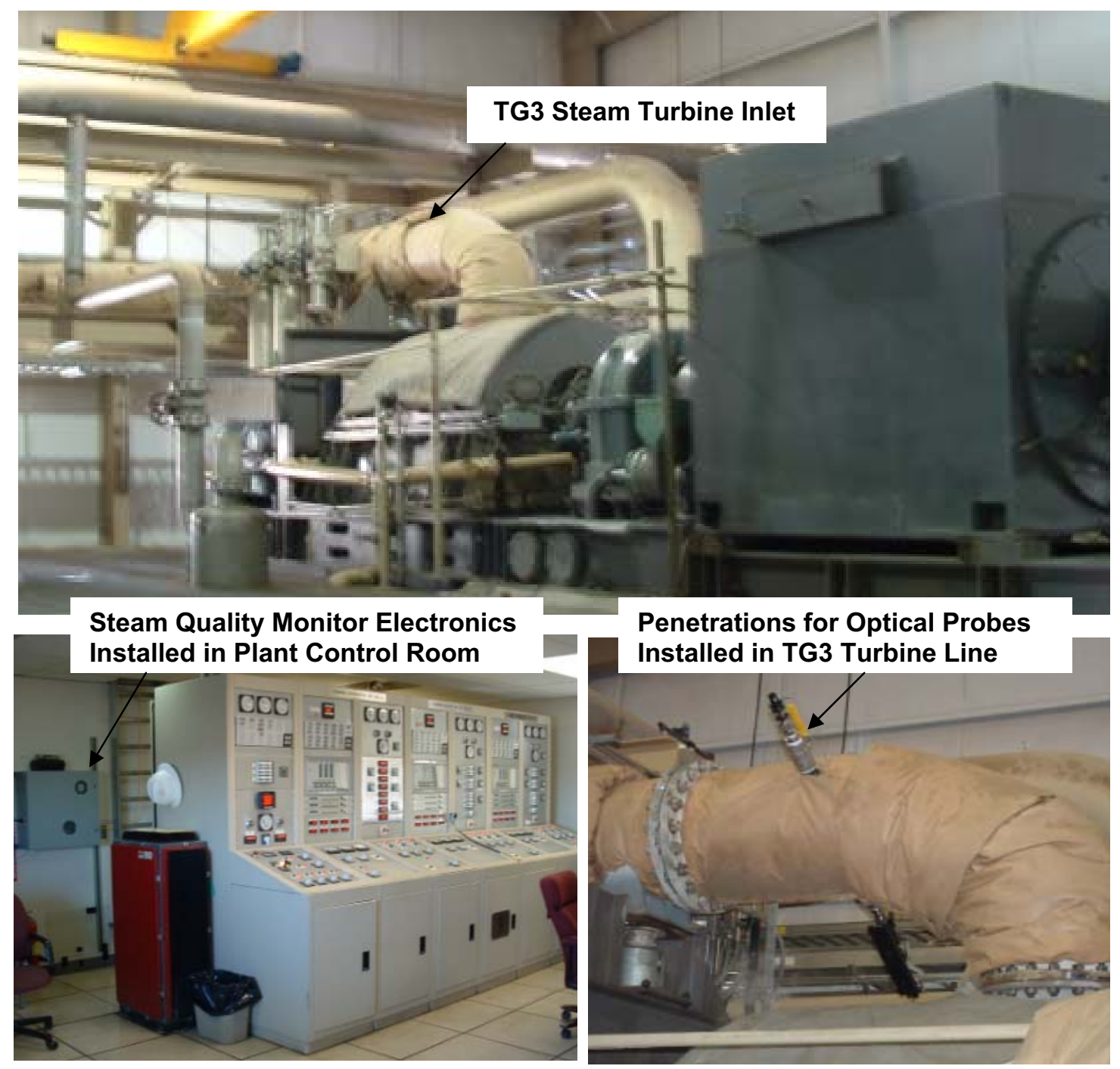

Figure 12. Optical steam quality monitor deployment at the Brady Power Plant.

The monitor was installed at the plant on August 20, 2003 and operated until January 17, 2004. The signals recorded were correlated with known changes in the plant operation, such as water washing, changes in the chemical treatments used for particulate inhibition, or other changes in plant operations which could impact steam quality. An example of the instrument's response during a washing cycle is presented in Figure 13. The graph shows a reduction in the vapor diode signal amplitude due to 
absorption and scattering as small quantities of water, 1.0-1.5 gallons per minute, were metered into the nominally $120,000 \mathrm{lb} / \mathrm{hr}$ steam flow.

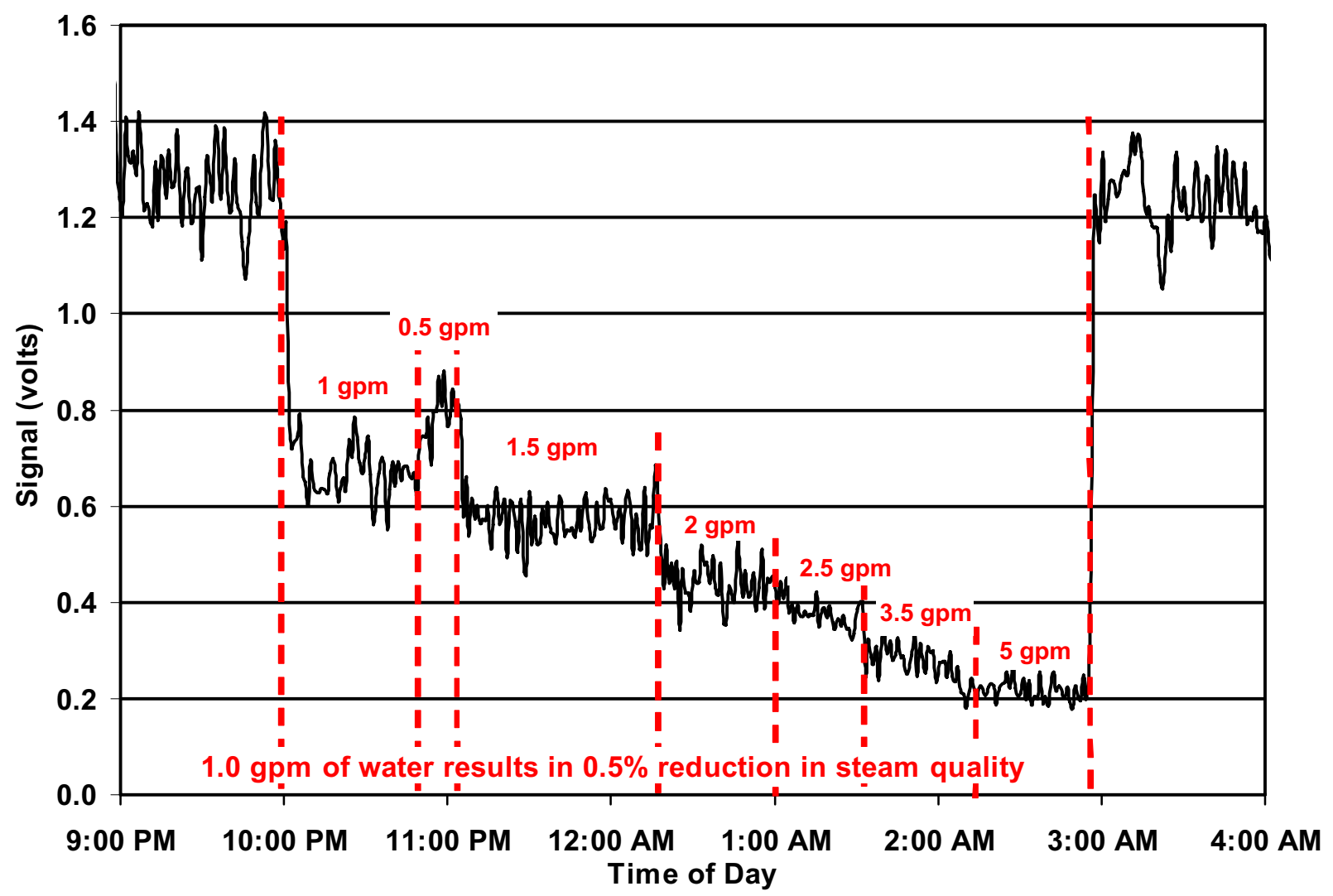

Figure 13. Steam quality monitor data collected during water washing procedure.

During the 150-day deployment, the device was able to successfully track small changes $(\sim 0.25 \%)$ in moisture content that occurred during scheduled operations such as turbine water washing used to reduce scale. In addition, the monitor also demonstrated the ability to alert operators to off-normal conditions in the plant, including a problem with one of the valve seals on a water wash isolation system. The instrument operated with minimal impact to the plant operation, and while there was some fouling of the window during the extended operation, no serious maintenance issues were discovered. In fact, the optical probes were never removed for cleaning or repair during the entire deployment.

A picture of one of the window probes after it was removed from the Brady turbine inlet line is presented in Figure 14. An analysis of the window using scanning electron microscopy and energy dispersive x-ray indicated the presence of silica, calcite and iron deposited on the window. These materials are found in entrained geothermal brine droplets, or in the case of iron, could also be a byproduct of corrosion in the system. The total mass of the solids deposited on the window was approximately 3 milligrams. 


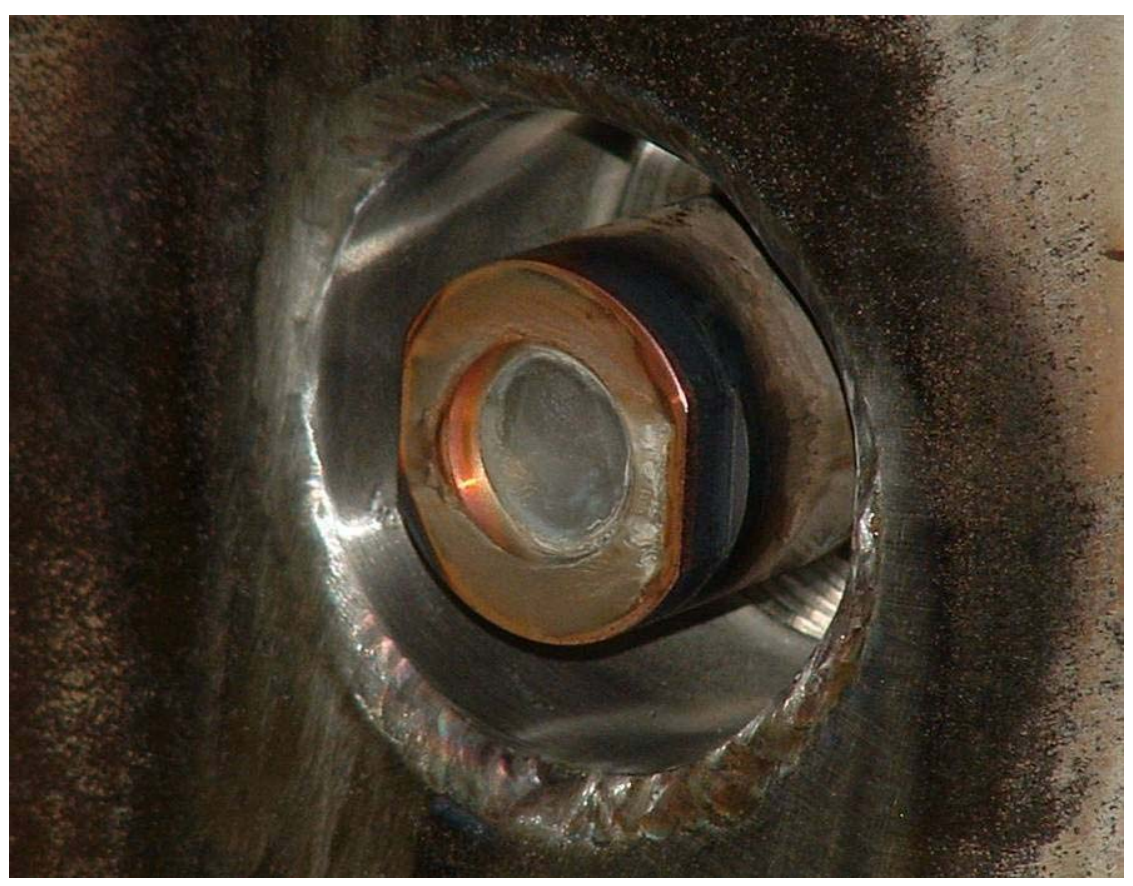

Figure 14. Steam monitor probe window condition after 150 day deployment in turbine inlet line. 


\section{PARTICULATE MEASUREMENTS}

\subsection{Technical Approach}

Several approaches have been investigated for the detection of particulate in geothermal process streams. These include technologies based upon laser spectroscopy, acoustic detection, particulate deposition, and light scattering measurements.

\subsubsection{Laser-induced Breakdown Detection (LIBD)}

A laboratory evaluation of a particulate characterization system based upon laser breakdown detection was conducted. Laser-induced breakdown occurs when high power laser pulses are focused onto a sample, such as particulate in a process stream. As illustrated in Figure 15, the intense radiation produced in the focal volume forms a high-temperature plasma and a pressure wave, or acoustic signal. The spectroscopic analysis of the plasma can be used to determine the elemental composition of the particle. The amplitude of the acoustic signal, as a function of laser energy, can be used to determine the particle size. (Larger energies are required to generate breakdown of smaller particles since they are less absorptive.) The particle concentration, or number density, is then determined by measuring the number of signals as a function of laser energy (Fujimori et. al., 1992; Bundschuh et. al., 2000). The level of spectral emission produced in the breakdown can also be used to infer particulate size and concentration.

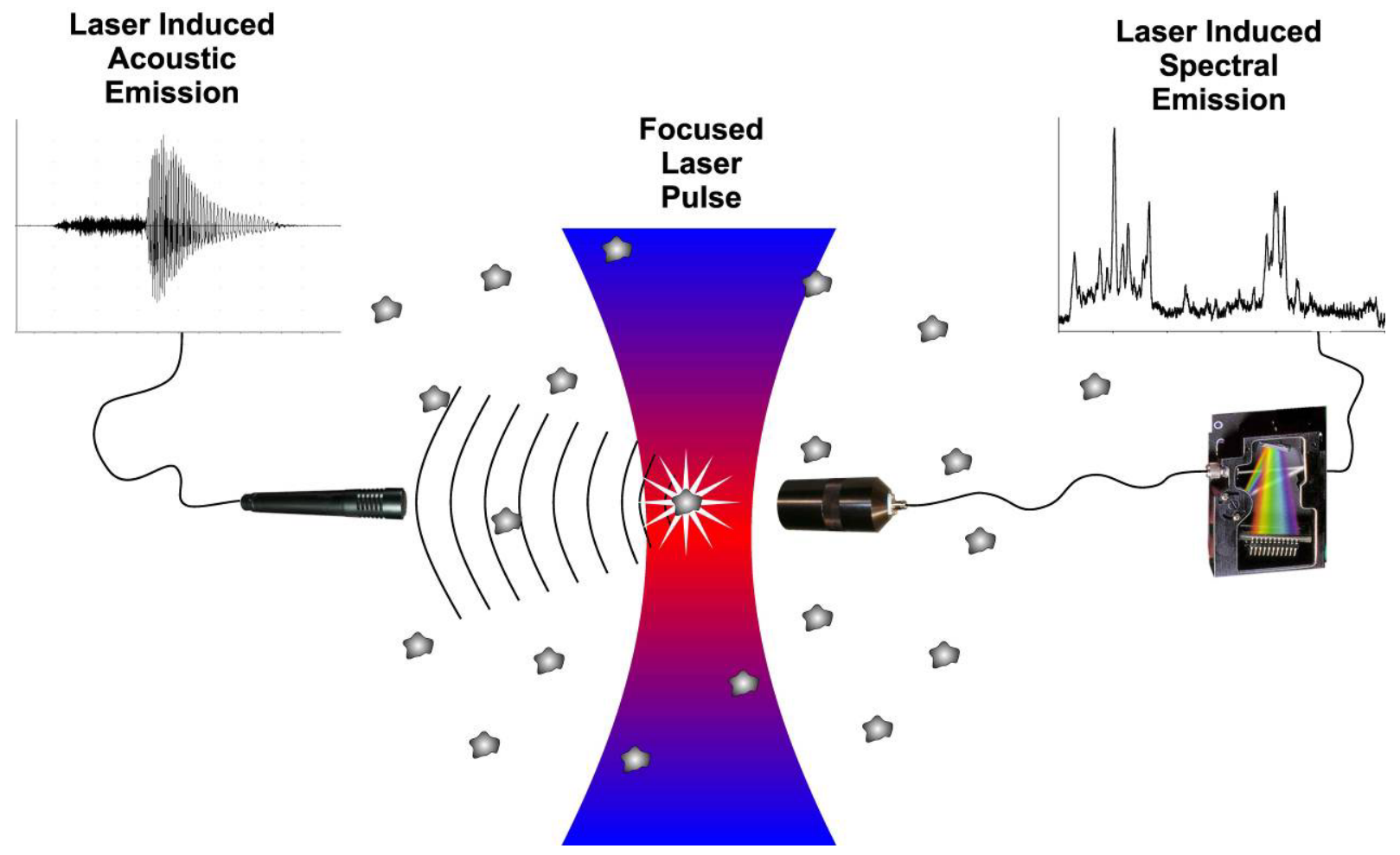

Figure 15. Laser-induced breakdown detection (LIBD) concept for detecting and analyzing particulate. 
LIBD technology is attractive for process applications since it can be designed to collect in-situ, real-time data in liquid, solid, or gaseous streams. It can also be very sensitive. Spectral and acoustic signals were successfully collected from laboratory prepared water samples spiked with low-density (1 ppm by weight) suspensions of sub-micron silica, iron, and alumina particulate (Partin and Davidson, 2002). Data were also successfully collected from water samples collected at geothermal plants.

However, LIBD is also a relatively complex and expensive technology to field and operate. A cost analysis indicated that the components required for integration of a field-ready system would cost on the order of $\$ 60,000$ to procure. The system would also require considerable effort to make it user-friendly for operator use; and in addition, there were concerns with its long term reliability under continuous operation in plant environments. (The high energy laser irradiation tends to damage optical interfaces over time, and this damage is more likely to occur when the components have surface contamination.)

\subsubsection{Particulate Deposition Monitoring}

Another possible approach to monitoring particulate in geothermal lines was discovered during the operation of the monitor in the turbine inlet line at the Brady Plant. As illustrated in Figure 16, the probe window fouling observed during that deployment was seen to decrease in amplitude at a rate of approximately $2.5 \%$ per day until day 34 , when a water washing cycle was performed. The signal amplitude is seen to recover around $75 \%$ of the pre-wash value then continue to decrease at approximately the same rate. This suggests that the window fouling could be used as an indicator of when washing is merited and could also be used to determine when internal components are sufficiently clean that the process could be terminated.

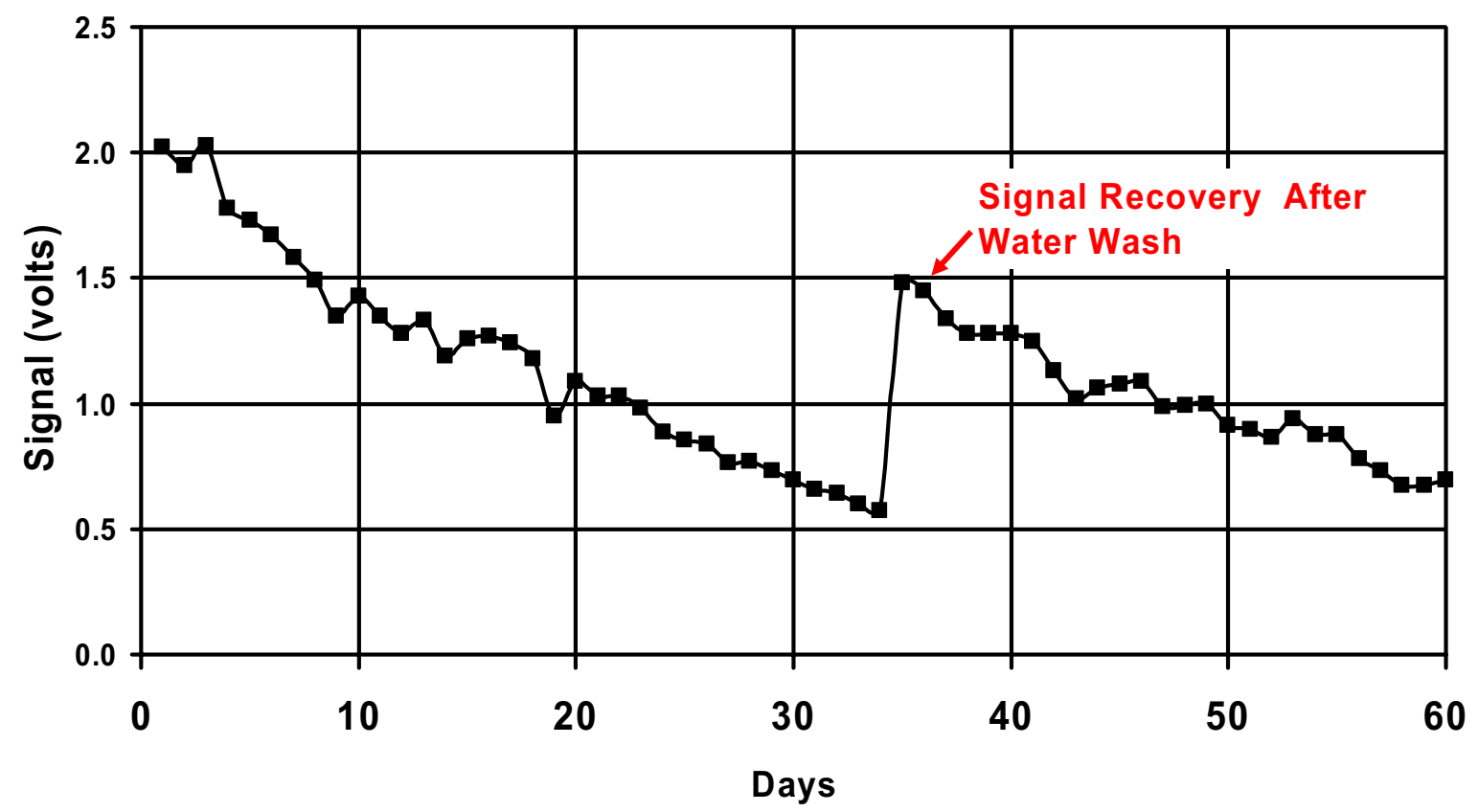

Figure 16. Change in steam quality monitor signal output due to particulate deposition, or fouling, on the probe windows.

If particulate deposition, or scaling, was the only parameter of interest, then a very simple instrument configuration could be envisioned. For example, a fiberoptically-coupled total attenuation reflectance optical component could be designed for insertion into the process line, allowing the sampling to be performed from a single port. 


\subsubsection{Light Scattering Measurements}

Since feedback from operators and other industry contacts on the optical steam quality monitor indicated a desire to measure not only moisture but also particulate in steam, the possibility of upgrading the existing optical steam quality instrumentation was investigated. As discussed in Section 2.1, the absorption coefficient, $\varepsilon$, in Beer's Law (Equation 1) governing the attenuation of a light signal as it travels through a substance may be attributed to two mechanisms. One is absorption by the molecular constituents; and the other, is scattering due to particulate found in the media (Laqua, et. al., 1988; Carlon and Wick, 1997). The magnitude of the scattered light depends upon a number of parameters including the wavelength and intensity of the incident radiation and the particulate refractive index, size, and concentration (Kerker and Cooke, 1976; Hirleman, 1980; Nicholls, 1984; Dick, 1998). The optical steam moisture monitoring instrumentation described in Section 2.2.2.1 was designed to average out and minimize the contributions of particulate to the signals. In addition, by choosing to measure two closely placed wavelengths which should produce nearly identical scattering coefficients, it was also possible to correct for the scattering contribution.

The key elements of the upgraded steam quality monitor design involve the use of a laser diode that is much less sensitive to water and water vapor and more responsive to scattering phenomena, as well as new processing techniques to recover this signal. A design has been developed, based upon timedivision multiplexing of the monitoring signals that would allow one channel of the device to serve as a particulate detector, providing real-time data on the mass concentration of solids flowing through the sample stream. The design reduces the averaging time and sampling volume, while increasing the probe power through pulsing of the lasers; thereby, enhancing particulate detection sensitivity. The basic concept is illustrated in Figures 17 and 18.

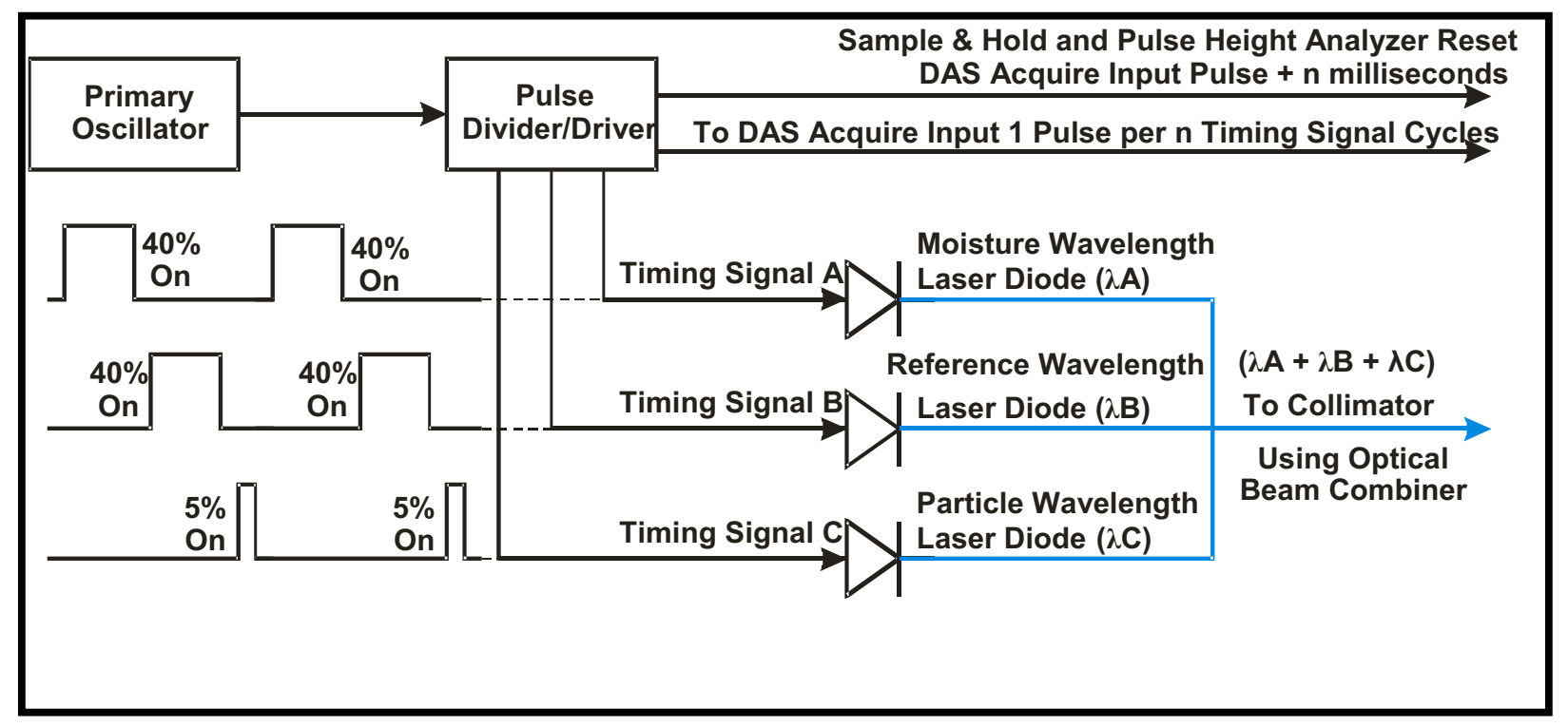

Figure 17. Schematic for the probe signal transmission in the upgraded monitor.

As shown in Figure 17, an oscillator feeds a pulse divider/driver circuit which provides all of the timing signals for laser duty cycle pulsing, sample and hold amplifiers, pulse amplifier, pulse height analyzer and data acquisition system (DAS) control. The moisture sensing laser, $\lambda \mathrm{A}$, and its reference wavelength laser, $\lambda \mathrm{B}$, are pulsed at a $40 \%$ duty cycle while the particulate sensing laser, $\lambda \mathrm{C}$, is pulsed at a $5 \%$ duty cycle. (The exact timing of the signals is based upon the process stream properties.) Ideally, the timing of the $\lambda \mathrm{C}$ pulse should be such that small particulate can travel through approximately $50 \%$ of the center 
beam during the duty cycle.) These pulses are produced serially with sufficient time between pulses to allow discrimination of the individual signals by the detector portion of the system. The outputs of the three laser wavelengths are combined using an optical beam combiner and transmitted via single mode fiber to the collimator located on the optical beam probe that penetrates into the steam process pipe. The output of this device produces a combined spectra beam that is transmitted across the measurement volume, collected by a second collimator, and focused into an optical fiber which propagates the signals to a photodiode detector. As illustrated in Figure 18, the output of the detector feeds two sample and hold amplifiers that are used for integrating the $\lambda \mathrm{A}$ and $\lambda \mathrm{B}$ signals used to determine steam moisture and the pulse sampler for the $\lambda \mathrm{C}$ signals used to monitor particulate.

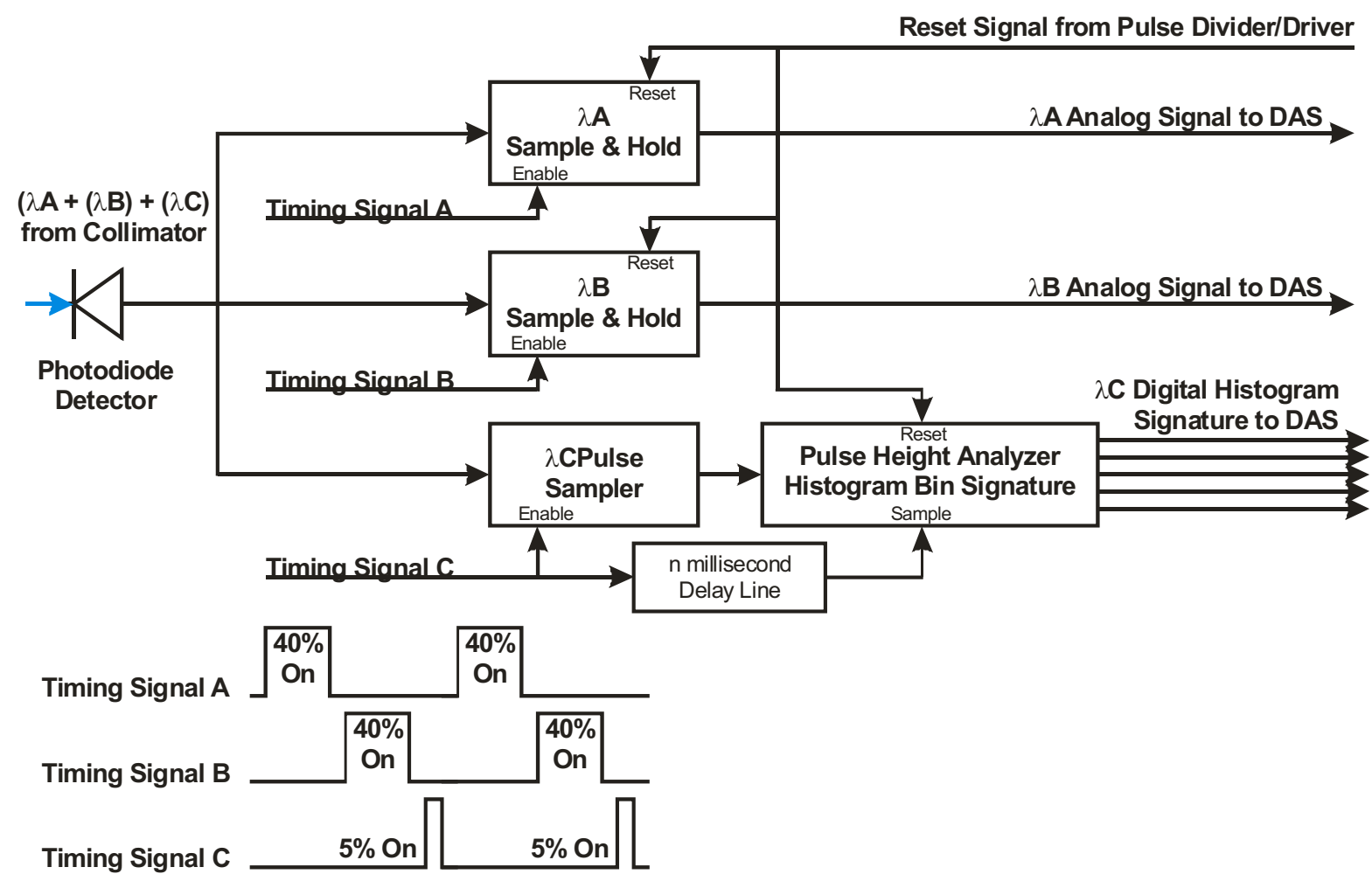

Figure 18. Schematic of the signal acquisition and processing in the upgraded monitor.

The sample and hold amplifiers for collecting the steam quality data are enabled by the appropriate timing signal from the pulse divider/driver circuit. These pulses are delayed and then shortened to produce a duty cycle of approximately $38 \%$ sampling only while the laser is on and at power. The amplifiers will continue to integrate until the data acquisition system is triggered to digitized and store a set of samples. After the acquisition of a complete sample set has occurred, a reset pulse is sent to the amplifiers to begin a new integration.

The pulse sampler for $\lambda \mathrm{C}$ on the other hand does not integrate over a long period of time. Its function is to isolate the $\lambda \mathrm{C}$ portion of the signal from the photodiode for processing by the pulse height analyzer. The pulse height analyzer utilizes a delayed timing signal, $\mathrm{C}$, to trigger a sample. The results of this single pulse are analyzed and binned based on amplitude. As the number of pulses continues, this analyzer continues to bin samples until the data acquisition system is ready for input. At this time the histogram output is sampled via digital lines by the data acquisition system for storage as a sample point 
data set. This allows the time tying of the signals from A and B and the histogram of $\mathrm{C}$ signals for post acquisition analysis. Once the histogram is retrieved by the data acquisition system, the pulse height analyzer is reset and the system begins obtaining a new histogram.

The move to a short time duration sample for the particulate wavelength and the subsequent histogram binning of the samples allows the monitoring of the quantity of particulate passing through the penetrating laser beam during an acquisition cycle. The type of data generated is depicted in Figure 19. In examining the histogram, histogram peaks with low intensity values indicate a large partial fraction of particulate matter in the measurement volume. Histogram peaks with higher intensity indicate a small partial fraction of particulate matter.

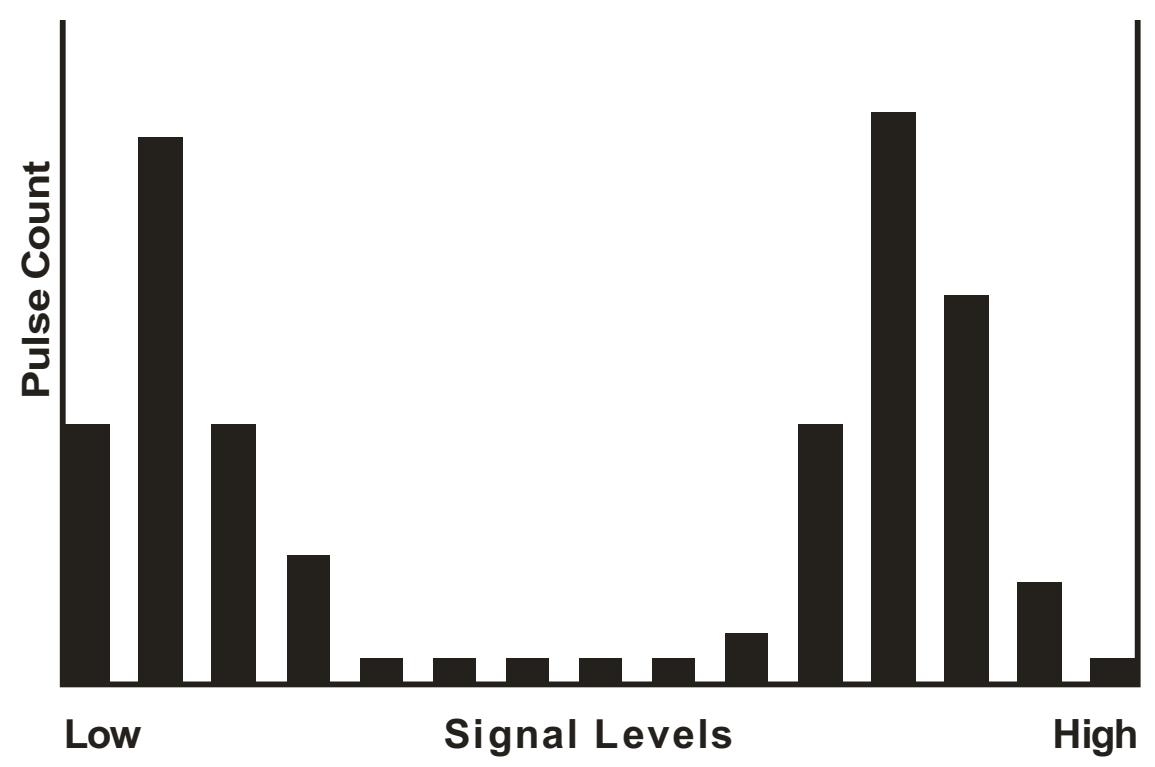

Figure 19. Presentation of particulate data in histogram format.

\subsection{Laboratory Experiments}

Laboratory experiments were conducted to investigate the performance of the particulate monitoring channel. In the experimental setup, shown in Figure 20, steam was produced using a commercial generator and propagated to a heated and insulated 0.8 meter long, flow-through test cell using a heated transfer hose. As in previous testing, the laser signals were transmitted to the windowed, test fixture through a fiber optic cable. The optical signals were then collimated into a beam of radiation that was transmitted through a sapphire window and across a sample cell where it was collected by an identical probe assembly and transmitted back to the electronics box for analyses. Particulate samples were generated using an electromagnetic vibrating, fluidized bed particle feeder. The particles were fed into the operating steam line using an air compressor and a valve system that could control the air flow through the vibrating particle feeder at a pressure differential of a few pounds per square inch above the line pressure. The amount of particulate was controlled by increasing the air flow and/or the vibration of the bed. The amount of the particulate fed into the system was established by collecting and weighing materials collected on filters as a function of the test conditions. This material was then compared with the quantity of steam flowing through the test cell during a comparable time period. 


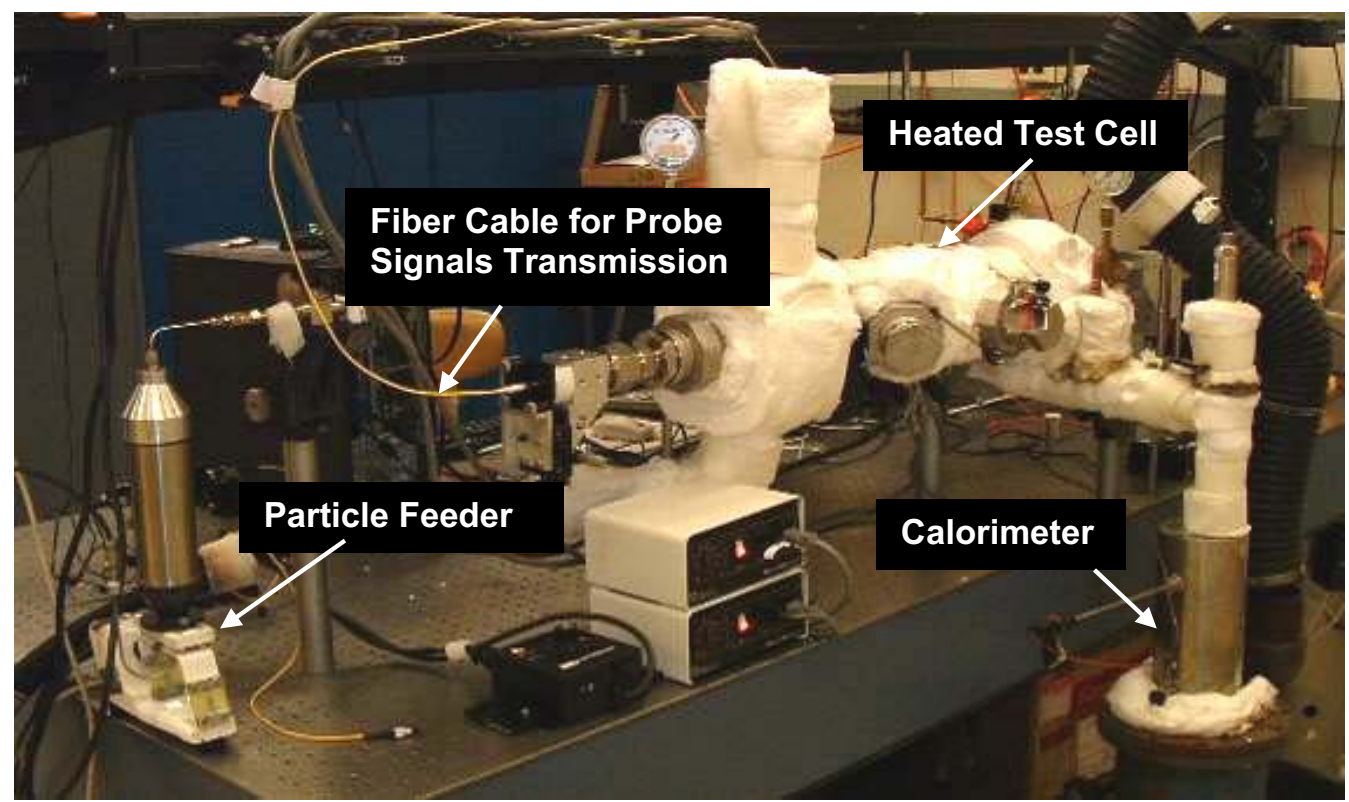

Figure 20. Experimental setup for particulate measurements.

Initial experiments were directed at validating that the diode selected for particulate monitoring was much less sensitive to moisture than the diodes used in the steam quality monitor tested at the Brady Plant. An example of one of these tests is illustrated in Figure 21. In this experiment, the laser diode signals propagated through the test cell are recorded with the cell operated at a temperature and pressure at which the steam flow is saturated. At around 70 minutes into the experiment the heaters are turned off and the vapor starts to become moist.

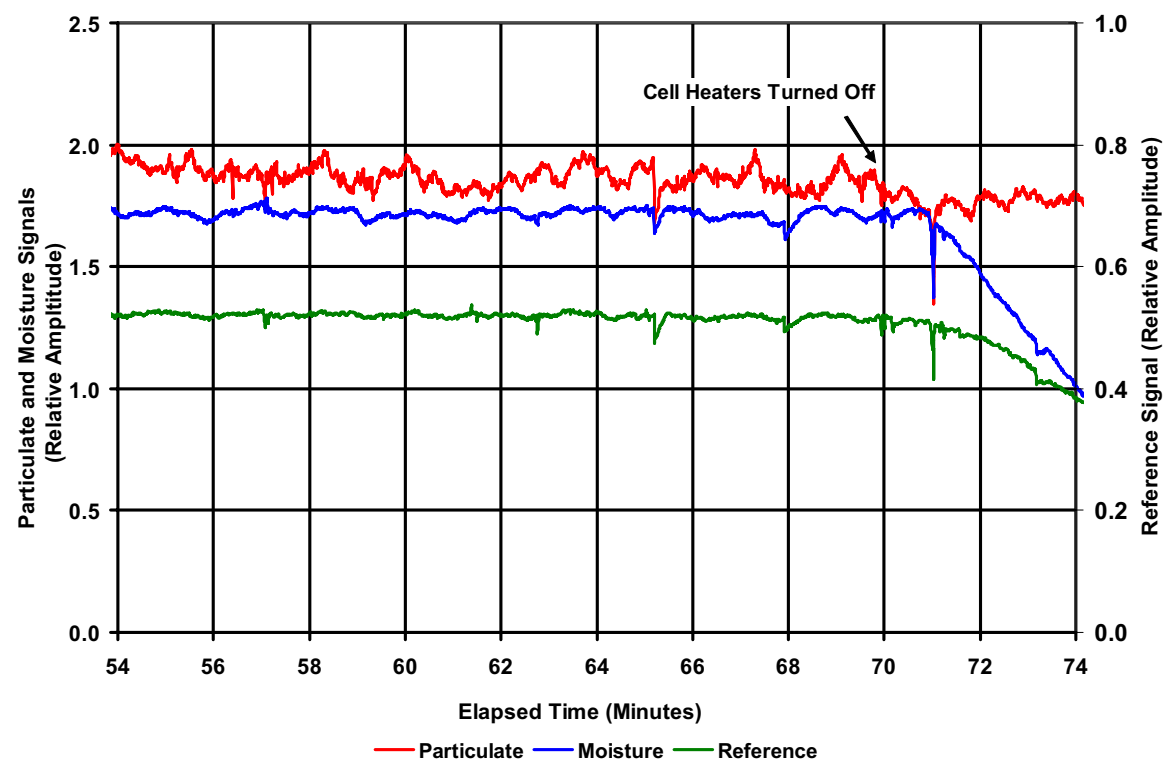

Figure 21. Comparison of the response of the new particulate monitoring diode, moisture sensing diode, and previously used reference diode to "dry" and "wet" conditions. 
When the steam quality is measured to be $99.6 \%$ at 74 minutes, the particulate laser has lost only $4 \%$ of its signal while the moisture sensing diode has lost $40 \%$ and the reference diode has lost around $25 \%$. These results clearly indicate that the new diode is much less sensitive to moisture than the previously used reference diode. However, one problem was noted with this particular laser diode during the testing. Referring again to Figure 21, the particulate sensing diode exhibits some sinusoidal variation and is generally noisier than the other diodes. After the testing was completed the diode was returned to the manufacturer who confirmed there was a problem with the electronics in this particular device. In a non-defective device, the noise characteristic would be comparable to the other diodes.

Figures 22 through 24 show the response of the new monitoring channel to the presence of small (10 micron average diameter) glass particulate in the 0.8 to 7.0 parts per million (ppm) concentration ranges. For the data collection, the test cell and steam line were heated to conditions where the steam was superheated. Pressurized air was then allowed to flow through the particulate feeder. After allowing one minute for conditions to stabilize, the vibration of the particle feeder was adjusted to a level predetermined to increase the concentration of particulate by a few ppm. The vibrator was turned off after one minute of operation and the data was collected for an addition two minutes. The data (pulse counts as a function of time) were sorted into $2 \%$ bins centered around the sensing diode's average signal.

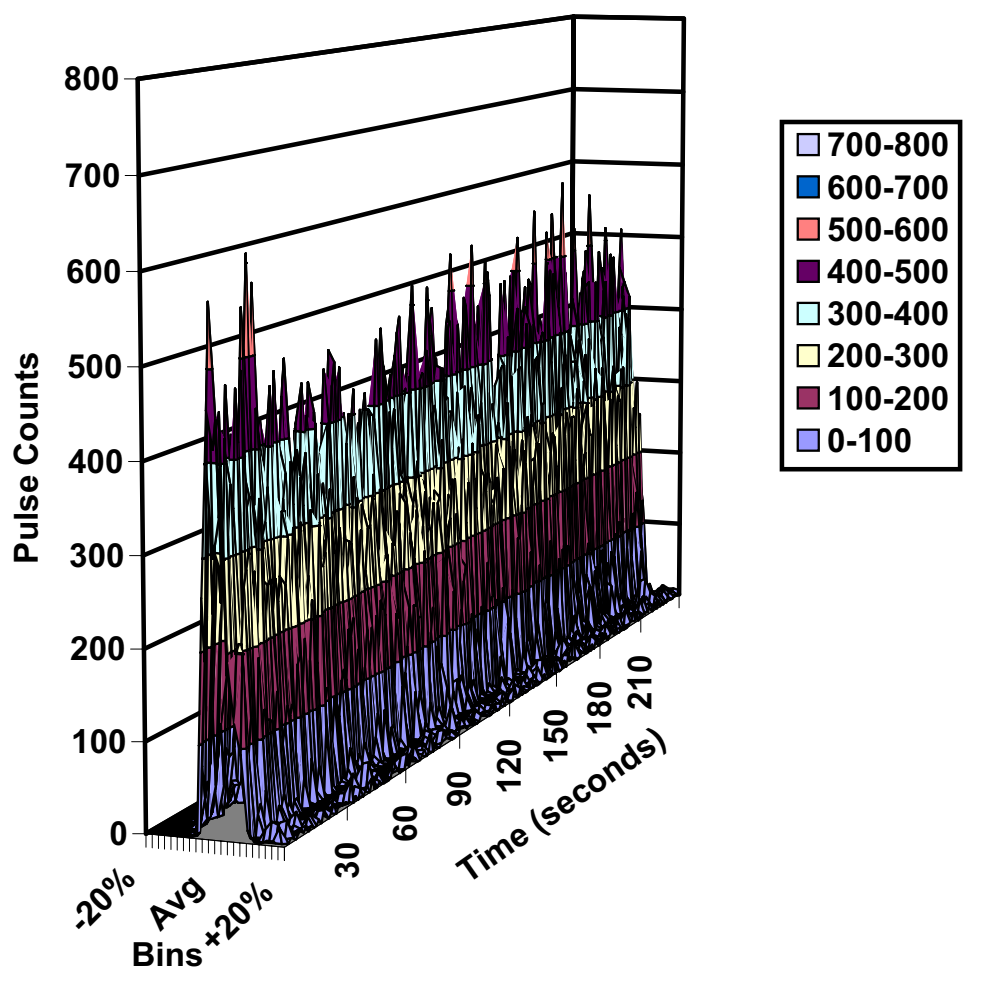

Figure 22. Change in pulse counts for a 0.8 ppm particulate feed. 

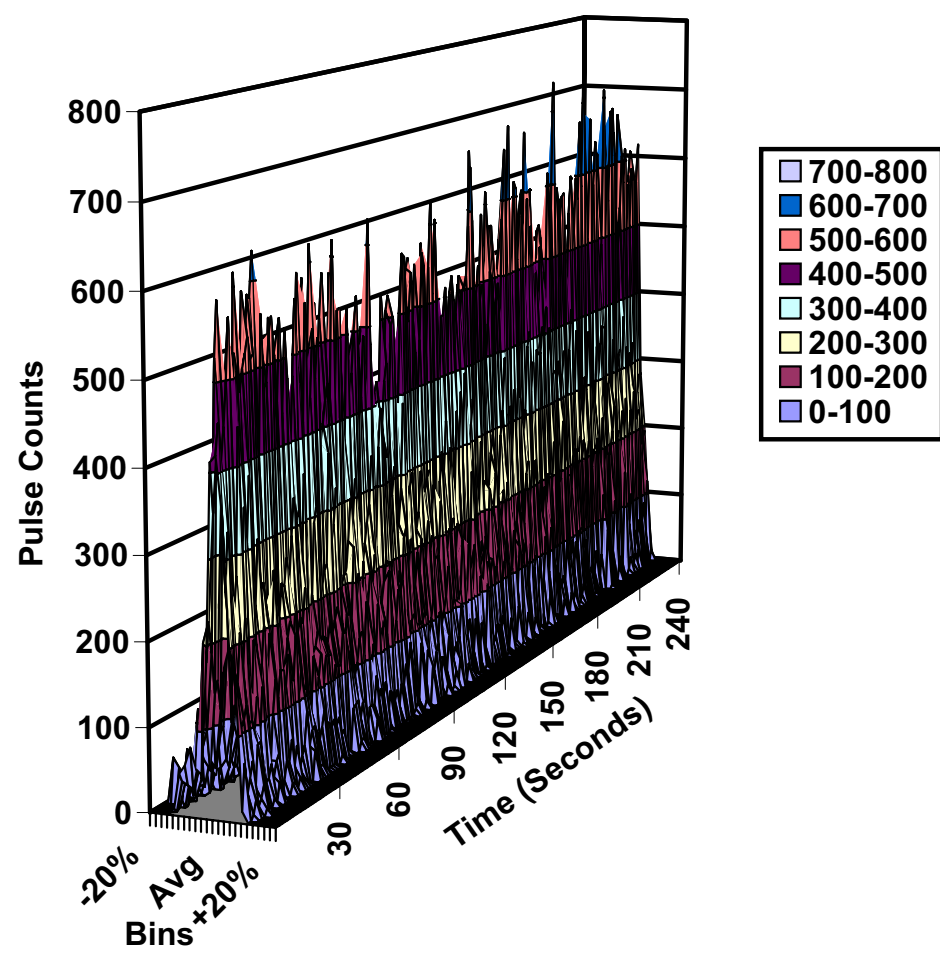

Figure 23. Change in pulse counts for a $2 \mathrm{ppm}$ particulate feed.

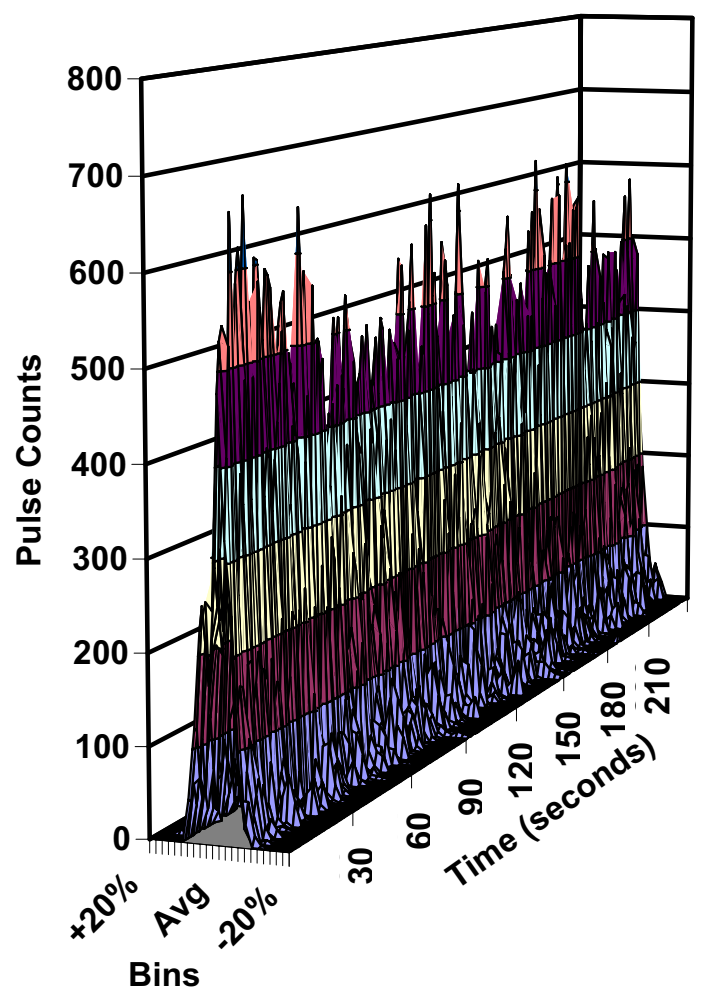

$\square 700-800$

$\square 600-700$

$\square 500-600$

$\square$ 400-500

$\square 300-400$

$\square$ 200-300

$\square$ 100-200

$\square 0-100$

Figure 24. Change in pulse counts for a $5 \mathrm{ppm}$ particle feed. 


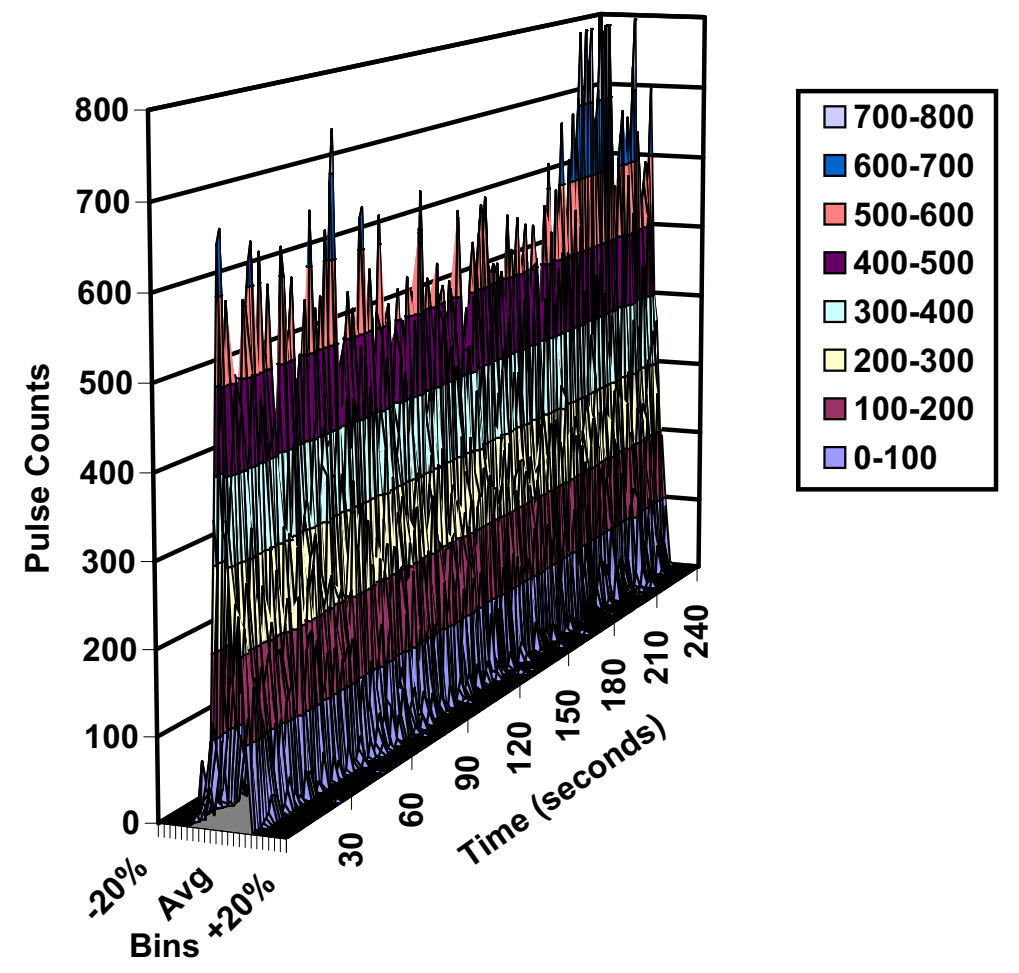

Figure 25. Change in pulse counts for a 7 ppm particulate feed.

Examining the plots, it is noted that there is a decrease in the pulse count number following the addition of more particulate to the system through increased agitation of the feeder at around 60 seconds. The drop in the number of counts is also larger and persists for a longer period of time at the higher concentrations tested. (It is speculated that it may take some time for the particulate to clear out of the inlet line to the cell after the feed vibrator is turned off.) While the operational variances made it difficult to establish a detection limit, the trend results at these low concentrations were encouraging since there are several measurement parameters that could be tuned to increase the measurement sensitivity. The most obvious fix is concerned with previously-described electronics problem that generated additional noise on the diode probe signal. If this noise had not been present the scattered signal discrimination would have been much better. In addition, the beam diameter propagating through the cell could be varied to increase the scattered signal intensity. The use of an off axis detection geometry might also improve the detection of the scattered light. 


\section{CONCLUSIONS}

A new optical steam quality monitor has been developed and tested. The monitor offers several advantages over existing techniques. The measurement is based upon a direct, rather than inferred, indication of the presence of water using very sensitive spectroscopic techniques for improved sensitivity and accuracy. The instrumental configuration is simple, compact, and can be fiberoptically-coupled to locations of interest. Open path measurements are possible allowing real-time data to be collected within a volume that extends through a cross-section of the process stream. This results in a more representative sampling of the stream and avoids the errors introduced into the measurements with point sampling of complicated flow regimes. The data can be recorded continuously with analyses available within seconds. The instrumentation can also operate over a wide range of moisture conditions.

The monitor was installed in a steam turbine inlet line at the Brady Power Plant for testing and evaluation. The in-situ installation and alignment of the valve assemblies for the probes was performed in less than 10 hours. During the 150 day deployment, the device was able to successfully track small changes in moisture content that occurred during scheduled operations such as water washing to reduce scale. In addition, the monitor also demonstrated the ability to alert operators to off-normal conditions in the plant. The instrument operated with minimal impact to the plant operation. No serious maintenance issues were discovered during the operation. In fact, the optical probes were never removed for cleaning or repair during the entire deployment.

The basic instrumentation platform can be modified and used to perform other measurements of interest to plant operators. In particular, an upgrade that will allow the instrument to be used for the sensitive detection of particulate in process streams has been investigated in the laboratory. The upgraded monitor design involves the use of laser diodes that are much less sensitive to water and water vapor and more sensitive to scattering phenomena, as well as new processing techniques to recover these signals. A design has been developed using time division multiplexing of the monitoring signals that allows one channel of the device to serve as a particulate detector, providing real-time data on the mass concentration of solids flowing through the sample stream. The design reduces the averaging time and sampling volume, while increasing the laser probe power, enhancing particulate detection sensitivity.

In addition to adding the ability to more sensitively detect particulate in process streams, the time division multiplexing design offers other advantages over the existing system. Since some of the more expensive custom components are not needed and the lifetime of pulsed lasers is generally longer than that of continuous wave lasers, the new design could result in an instrument that is less expensive to fabricate, operate, and maintain. 


\section{REFERENCES}

Bundschuh, T. et. al., 2000. "Application of LIBD to the Determination of the Solubility Product of Thorium(IV)- Colloids,” Radiochimica Acta, vol. 88/9, pp. 625- 629.

Carlon, H. R. and Wick, C. H., February 1997, Backscatter and Transmission of Aerosol at UV Through Middle IR Wavelengths, Report Number ERDEC-TR-396, Edgewood Research, Development, and Engineering Center, Aberdeen Proving Ground.

Dick, V. P., 1998, “Applicability Limits of Beer's Law for Dispersion Media with a High Concentration of Particles," Appl. Opt., vol. 37, pp. 4998-5004.

Fujimori, H. et. al., 1992. "Detection of Fine Particles in Liquids by Laser Breakdown Method," Jpn. J. Appl. Phys., vol. 31, pp. 1514-1518.

Gallup, D. L.,1998. “Aluminum Silicate Scale Formation and Inhibition (2): Scale Solubilities and Laboratory and Field Inhibition Tests," Geothermics, vol. 27, pp. 485-501.

Hirleman, E. D., 1980, "Laser-based Signal Particle Counters for In Situ Particulate Diagnostics'”, Opt. Eng., vol. 19, pp. 854-860.

Jung, D.B., 1995. "Geothermal Steam Quality Testing," Geothermal Resources Council Transactions, vol. 19 , p. 575-583.

Kerker, M. and Cooke, D. D., 1976, "Remote Sensing of Particle Size and Refractive Index by Varying the Wavelength,” Appl. Opt., vol. 15, pp. 2105-2111.

Kou, L., Labrie, D. and Chylek, P.,1993, "Refractive Indices of Water and Ice in the 0.65- to 2.5- $\propto \mathrm{cm}$ Spectral Range,” Appl. Opt., vol. 32, pp. 3531-3540.

Laqua K., Melhuish, W. H., and Zander, M., 1988, "Molecular Absorption Spectroscopy," Pure and Appl. Chem., vol. 60, pp. 1449-1460.

Nicholls, R. W., 1984, "Wavelength-dependent Spectral Extinction of Atmospheric Aerosols," Appl. Opt., vol. 23, pp. 1142-1143.

Palmer, K. F. and Williams, D., 1974, "Optical Properties of Water in the Near Infrared", J. Opt. Soc. Am., vol. 64, pp. 1107-1110.

Partin, J.K. and C. L. Jeffery, 1998. "Investigation of Near-Infrared Diode Laser Spectroscopy for $\mathrm{H}_{2} \mathrm{~S}$ Monitoring in Geothermal Plants," Geothermal Resources Council Transactions, vol. 22, pp. 435-439.

Partin, J. K. and J. D. Davidson, 2002. "Investigation of Optical Technologies for Measuring Geothermal Fluid Properties," Geothermal Resources Council Transactions, vol. 26, pp. 739-743.

Partin, J. K., J. R. Davidson, E. N. Sponsler, and G. L. Mines, 2004, "Deployment of an Optical Steam Quality Monitor in a Steam Turbine Inlet Line," Geothermal Resources Council Transactions, vol. 28, pp. 557-560. 
Wexler, A., Ed., 1963. Principles and Methods of Measuring Humidity in Gases, Reynold Publishing Corporation, New York, New York. 